\title{
Klaus-Jürgen Müller
}

\section{„Faschismus“ in Frankreichs Dritter Republik?}

\author{
Zum Problem der Überlebensfähigkeit der französischen \\ Demokratie zwischen den Weltkriegen
}

I.

Das Thema ist zu komplex, als daß es auf begrenztem Raum erschöpfend abgehandelt werden könnte. Daher kann es nur darum gehen, einige methodische Überlegungen anzustellen und an einigen Beispielen zu erproben, wie man „faschistische" Erscheinungen in Frankreich erfassen, beschreiben und in Grenzen erklären kann. Zur schärferen Konturierung und zur Herausarbeitung der französischen Spezifika sollen diese punktuell vor den Hintergrund der deutschen Entwicklung gestellt werden.

Der Ansatz wirft mehrere methodische Probleme auf. $\mathrm{Da}$ ist erstens das Problem der Vergleichbarkeit. In Frankreich hat sich der "Faschismus“ nicht die Macht im Staat aneignen können; einen 30. Januar 1933 hat es dort nicht gegeben. Das führt zu der Frage, warum Frankreichs Dritte Republik nicht wie die Republik von Weimar an sich selbst, gleichsam von innen, zugrunde gegangen ist, sondern erst unter dem Angriff deutscher Panzerarmeen zerbrach. Außerdem ist ein diachronischer Ansatz erforderlich. Jedenfalls wird man für Frankreich die Untersuchung bis ins Jahr 1939 weiterführen müssen. Mit Kriegsbeginn und vollends mit der militärisch-politischen Niederlage von 1940 trat eine grundlegend veränderte Gesamtsituation ein, die neue Kategorien der Beurteilung erforderlich macht. Das wird oft übersehen. Dadurch wird die Entwicklung im Frankreich der Zwischenkriegszeit häufig von der Kriegszeit her bewertet. Das jedoch verzerrt Ereignisse und Zusammenhänge nicht unerheblich.

Schwieriger noch ist das zweite Problem, das Problem der Begrifflichkeit. Der Begriff Faschismus als genereller Begriff, als Gattungsbegriff, ist seit Anfang der sechziger Jahre v. a. durch Ernst Noltes Werk in die geschichtswissenschaftliche und politologische Debatte wieder eingeführt worden. Fortan wurde mit beeindruckendem intellektuellem Aufwand versucht, bestimmte politische Phänomene unter diesen Begriff zu subsumieren. Eine solche Verwendung ist in mehrfacher Hinsicht problematisch. „En France“ - so schrieben die Verfasser eines der ersten Arbeiten über französischen ,Faschismus' - „on est toujours, ou l'on a été, le fasciste de quelqu'un 1." In diesem Paradoxon wird der politisch-polemische Charakter des Begriffes und dessen völlige Beliebigkeit angesprochen². Entstanden ist er bekanntlich als Selbstbezeichnung der italienischen Mussolini-Bewegung. Fast

1 Jean Plumyène/Raymond Lasierra, Les Fascismes Français 1923-1963, Paris 1963, S. 9.

2 Beliebigkeit und Polemikcharakter, ja die Absurdität des Begriffes kommen in der bekannten, von Jürgen Habermas geprägten Formel vom „Faschismus von Links“ treffend zum Ausdruck. 
gleichzeitig wurde er als polemisch-abwertende Feindbezeichnung von deren Gegnern adoptiert. Seither hat die politische Sprache den polemischen Charakter des Begriffes überdeutlich werden lassen. Angesichts dessen hätten mindestens die Historiker Hemmungen haben müssen, einen Begriff generalisierend und epochenüberschreitend zu benutzen. Die unhistorische Generalisierung sowie die politisch-polemische Verwendung dieses Begriffes sollten daher eigentlich genügen, um ihn aus der wissenschaftlichen Diskussion zu verbannen. Er richtet mehr Unklarheit und Verwirrung an, als daß er analytische Trennschärfe und Erklärungskraft beweist. Für den unvoreingenommenen Betrachter läßt die internationale "Faschismus-“Forschung ${ }^{3}$ die Problematik dieses Gattungsbegriffes, insbesondere in seiner Verwendung bei komparatistischen Ansätzen, eindeutig erkennen. Selbst ein so engagierter Verfechter eines generalisierenden Faschismus-Begriffes wie Jürgen Kocka hat schon vor über zwanzig Jahren eingeräumt, daß man mit diesem Begriff "große Schwierigkeiten" habe, denn er sei überwiegend vom deutschen und italienischen Beispiel abgeleitet worden und seine Ausdehnung auf andere Bewegungen und Herrschaftssysteme führe leicht zu unscharfen Überdehnungen ${ }^{4}$. Aber trotz dieser völlig zutreffenden Einsicht wird immer noch in weitem $\mathrm{Maße}$ an diesem zutiefst problematischen Begriff festgehalten.

Ein Blick in das Werk von Ernst Nolte enthüllt die Problematik ${ }^{5}$. Nolte hat in seinem monumentalen Werk "Der Faschismus in seiner Epoche“ aufgrund einer Analyse dreier historischer Erscheinungen, nämlich der "Action Française“ (A.F.), dem italienischen Faschismus und dem Nationalsozialismus, einen „geschichtsphilosophisch"6 geprägten Faschismus-Begriff entfaltet. Eine Übertragung auf andere als faschistisch angesehene Bewegungen im Europa der Zwischenkriegszeit ist ihm dann jedoch mißlungen. Er mußte nämlich in dem Werk „Die Krise des liberalen Systems" sein zentrales Faschismus-Kriterium des „Transpolitischen" aufgeben zugunsten eines phänomenologischen Ansatzes, mit dem er schließlich in der Addition von „faschistischen Merkmalen“ zu einem „faschistischen Minimum“ von sechs „Fundamentalmerkmalen“ gelangte. Angesichts der Vielfalt der angeblich „faschistischen“ Erscheinungen mußte er aber einräumen, daß unter Umständen nicht einmal alle Kriterien dieses „Minimums“ vollständig gegeben sein müßten. Wieso dann Minimum? Karl Dietrich Bracher hat angesichts der Übertragungsproblematik dezidiert dafür plädiert, auf die Verwendung eines generalisierenden Faschismusbegriffes überhaupt zu verzichten?

3 Allgemein hierzu die Arbeiten von Wolfgang Wippermann, Faschismustheorien. Zum Stand der gegenwärtigen Diskussion, Darmstadt ${ }^{71997}$; ders., Europäischer Faschismus im Vergleich 19221982, Frankfurt a. M. 1983; ders./Hans-Ulrich Thamer, Faschistische und Neofaschistische Bewegungen, Darmstadt 1977.

4 Jürgen Kocka in: Totalitarismus und Faschismus. Eine wissenschaftliche und politische Begriffskontroverse. Kolloquium des Instituts für Zeitgeschichte, München, 24. November 1978, München/Wien 1980, S. 43.

5 Ernst Nolte, Die faschistischen Bewegungen, dtv-Weltgeschichte des 20. Jahrhunderts, Bd. 4, München 1966, S. 315, Anm. 127 und S. 294; vgl. auch die Neuedition unter dem Titel: Die Krise des liberalen Herrschaftssystems und die faschistischen Bewegungen, München 1968.

6 Ernst Nolte, Philosophische Geschichtsschreibung heute?, in: Historische Zeitschrift 242 (1986), S. 265-289.

7 Karl Dietrich Bracher, Kritische Betrachtungen zum Faschismusbegriff, in: ders., Zeitgeschichtliche Kontroversen um Faschismus, Totalitarismus, Demokratie, München 1974, 51984, S. 13-33. 
u. a. auf eines der zentralen Probleme, nämlich daß das essentielle Element des $\mathrm{Na}$ tionalsozialismus, der rassistische "Vernichtungs"-Antisemitismus, in den meisten anderen „Faschismen“ nicht zu finden ist ${ }^{8}$.

Die Zweifel an der Brauchbarkeit eines generellen Faschismus-Begriffes vermehren sich noch, wenn man die Versuche in den Blick nimmt, die gemacht wurden, um die extremistischen Erscheinungen im Frankreich der Zwischenkriegszeit faschismustheoretisch zu erfassen. Bislang ist nämlich keine Einhelligkeit in der Literatur darüber erzielt worden, ob und welche der in Frage stehenden Erscheinungen in Frankreich wirklich „faschistisch“ gewesen sind oder nicht. René Rémond ${ }^{9}$ und mit ihm eine ganze Schule von Faschismus-Forschern kommen unter Verwendung eines schematischen ideengeschichtlichen Rasters zu dem Ergebnis, es habe gar keinen französischen Faschismus gegeben; einige Gruppen der Rechten und der extremen Rechten hätten sich nur zeitweilig eine „faschistische Färbung" gegeben. Vielmehr könnten diese Erscheinungen in die drei Traditionslinien der französischen Rechten eingeordnet werden: den gegenrevolutionären Legitimismus, den liberal-konservativen Orleanismus und den autoritär-plebiszitären Bonapartismus. Die extremistischen Bewegungen der Rechten in der Zwischenkriegszeit werden daher nicht als "faschistisch" aufgefaßt, sondern in die bonapartistische Tradition eingeordnet. Ganz im Gegensatz dazu kommt Zéev Sternhell mit derselben ideengeschichtlichen Methode zu dem Ergebnis, daß Frankreich geradezu als das „kulturelle Mutterland“ der faschistischen Ideologie anzusehen sei ${ }^{10}$. Diese Diskrepanz zeigt, daß eine noch so subtile ideengeschichtliche Ableitung und Erklärung des „Faschismus“ ganz und gar keine eindeutigen und schon gar keine stringenten Ergebnisse bietet.

Angesichts dieser widersprüchlichen Resultate der phänomenologischen und ideengeschichtlichen Ableitungsversuche hat eine andere Denkschule der französischen Forschung die (vor allem in der deutschen und angelsächsischen Geschichts- und Sozialwissenschaft besonders gepflegte) faschismustheoretische Diskussion aufgegriffen. Pierre Milza hat in Frankreich erstmals eine inbaltliche

$8 \mathrm{Zu}$ Noltes Auseinandersetzung mit dem zentralen Einwand von Bracher (s. Anm. 5) vgl. Ernst Nolte, Kapitalismus, Marxismus, Faschismus, in: ders., Marxismus, Faschismus, Kalter Krieg. Vorträge und Aufsätze 1964-1976, Stuttgart 1977; und ders., Der europäische Bürgerkrieg 19171945. Nationalsozialismus und Kommunismus, Frankfurt a. M. 1987; sowie ders., Vergangenheit, die nicht vergehen will, in: „Historiker-Streit ${ }^{*}$. Die Kontroverse um die Einzigartigkeit der nationalsozialistischen Judenvernichtung, München 1987, S. 39-47. Zur Kritik an Noltes Bestreben, den generellen Faschismusbegriff dadurch zu „retten“, daß er den Rassen-Antisemitismus des „radikalfaschistischen" Nationalsozialismus zur Extremform des Antimarxismus/Antibolschewismus erklärt, vgl. die scharfsinnige Analyse bei Andreas Wirsching, Vom Weltkrieg zum Bürgerkrieg? Politischer Extremismus in Deutschland und Frankreich 1918-1933/39. Paris und Berlin im Vergleich, München 1999, S. $513 \mathrm{ff}$.

9 René Rémond, Les Droites en France, Paris 1982; und ders., Y-a-t-il un fascisme français?, in: Terre Humaine, Nr. 7-8 (1952), S. 37-47; ähnlich auch Philippe Machefer, Ligues et Fascismes en France 1919-1939, Paris 1974 (Dossier Clio).

10 Zéev Sternhell, Maurice Barrès et le Nationalisme français, Paris 1972; ders., La Droite révolutionnaire. Les origines françaises du fascisme 1885-1914, Paris 1978; ders., Ni droite, ni gauche. L'Idéologie Fasciste en France, Paris 1983, 21987. Zur französischen Kritik an Sternhell vgl. u.a. Serge Berstein, La France des Années Trente allergique au fascisme? À propos d'un livre de Zéev Sternhell, in: Vingtième Siècle Nr. 2 (April 1984), S. 83-94; und Jacques Juillard, Sur un fascisme imaginaire, in: Annales ESC, Bd. 39/2 (1984), S. 849-861. 
Definition von Faschismus zu entwickeln versucht ${ }^{11}$. Damit reiht er sich in den Reigen derer ein, die subtile terminologische Differenzierungen nominalistischer Natur aufstellen und sich um die Konstruktion eines "faschistischen Idealtypus" bemühen. Auf der Grundlage der Überlegungen Pierre Milzas entwickelte Philippe Burrin ${ }^{12}$ eine weitere, noch subtilere Faschismusdefinition'13. Ihre Anwendung auf einige französische Phänomene brachte jedoch keine sehr verheißungsvollen Ergebnisse. Die angesprochenen Erscheinungen ließen sich nämlich nur sehr unvollständig und annäherungsweise unter diese Definition subsumieren. So mußte Burrin seine Zuflucht zu vagen und nebulösen Begriffen nehmen wie „fascistoïde“, ,imprégnation fasciste“ bzw. „contagion fasciste“ oder auch „ensemble fascisant", Formeln, die weder eine präzise Beschreibung noch gar eine Erklärung enthalten ${ }^{14}$. Die Ergebnisse solcher Art nominalistischen Vorgehens legen ebenfalls den Schluß nahe, daß derartige faschismustheoretische Analysen für die Erklärung und Beschreibung der französischen Phänomene wenig tauglich sind ${ }^{15}$.

Diese Feststellung wird auch durch den methodisch überaus reflektierten Versuch einer Problemlösung, den kürzlich Andreas Wirsching unternommen hat, nicht widerlegt. Er zeigt vielmehr, wie schwierig es ist, den Aporien der faschismustheoretischen Erklärungen zu entgehen. Wirsching schlägt einen modifizierten totalitarismustheoretischen Ansatz vor. Er macht sich die von der klassischen Totalitarismustheorie herausgestellten idealtypischen Kennzeichen totalitärer Herrschaft für die Analyse von extremistischen Bewegungen nutzbar. Für ihn fällt so der Nationalsozialismus aus dem vom „Faschismus“-Begriff abgedeckten Bereich heraus. Mit Bracher hält er den "rasseantisemitischen Ideologiekern“ des Nationalsozialismus für „einzigartig“16. Damit entziehe sich die NS-Bewegung

1 Pierre Milza, Fascisme Français. Passé et Présent, Paris 1987; sowie ders., Les Fascismes, Paris 1985, speziell Kap. V.

12 Philippe Burrin, La Dérive fasciste. Doriot, Déat, Bergéry 1933-1945, Paris 1986, speziell S. 11-28 und S. 447-456; ders., Le fascisme, in: Jean-François Sirinelli (Hrsg.), Histoire des droites en France, 3 Bde., Paris 1992, Bd. 1, S. 603-652.

13 "Le fascisme ambitionnait de former une communauté nationale mobilisée en permanence sur des valeurs de foi, de force et de combat; une communauté inégalitaire, comprimée dans une unité totalitaire excluant toute autre allégeance que la fidélité exclusive à un chef qui personnifiait le destin collectif et en décidait absolument; une communauté militarisée, soudée en vue d'une entreprise de domination qui était en elle-même son principe et son but." Von dieser Definition ausgehend versucht Burrin, den Grad der „fascisation“ einer Erscheinung zu bestimmen.

14 Kritische Würdigung der Arbeit von Burrin bei Klaus-Jürgen Müller, „Faschisten“ von Links?, in: Francia 17/3 (1990), S. 170-191. Zu ähnlichen Ergebnissen wie Burrin kommt Reinhold Brender, Kollaboration im Zweiten Weltkrieg. Marcel Déat und das Rassemblement National Populaire, München 1992; vgl. dazu meine Bemerkungen in: „Linksintellektuelle“ und „Faschisten“, in: Francia 21/3 (1994), S. 159-169.

15 Der Vorschlag von Hans Mommsen, Die NSDAP. Typus und Profil einer faschistischen Partei, in: Christof Dipper/Rainer Hudemann/Jens Petersen (Hrsg.) Faschismus und Faschismen im Vergleich, Köln 1989, S. 23-35, den Faschismuscharakter in der spezifischen Form der politischen Mobilisierung zu sehen, der ein rein instrumentales Politikverständnis entspricht, ist fraglos ein operationeller Fortschritt gegenüber allen geistesgeschichtlichen und ideologisch-inhaltlichen Definitionen. Letztlich verweist der so definierte "Faschismusbegriff“ auf das Phänomen der Formveränderung der Politik. Seine komparatistische Brauchbarkeit bleibt noch zu erproben.

16 Das Spezifikum der NS-Bewegung, der rassistische, auf Vernichtung abgestellte Antisemitismus, sei - wie Bracher gegen Nolte betont - keinc unmittelbare Antwort auf die kommunistische Bedrohung gewesen, sondern er sei älteren, eigenständigen Denktraditionen, vornehmlich der völkisch-antisemitischen Ideologie, entsprungen. Diese im Vergleich zum Bolschewismus ältere Ideologie habe bereits einen antiliberalen Kern gehabt; vgl. hierzu auch Wirsching, Weltkrieg, S. 522. 
„dem Vergleich mit anderen Faschismen17.“ Rassenantisemitismus und Faschismus seien somit als „analytisch streng zu unterscheidende, distinkte Potentiale“ zu begreifen. Vom „italienischen Ursprungsphänomen“ ausgehend entwickelt Wirsching sodann - in Anlehnung an Nolte, Payne ${ }^{18}$ und Burrin - einen „faschistischen Idealtypus“, der „Elemente des typologischen Verfahrens aufnimmt, sich aber auf das antimarxistische Merkmal konzentriert". Zu dem zentralen Element des Antikommunismus kommen als Faschismus-Kriterien zwei andere „faschistische Negationen" noch hinzu: Antiliberalismus und Antikonservatismus. Weitere Indikatoren sind für ihn Führerkult, Massenmobilisierung, eine hierarchische Partei mit einem (mindestens rudimentär vorhandenen) geheimpolizei-ähnlichen Sicherheitsdienst und eine paramilitärische Organisation. „Ihren funktionalen Zusammenhalt gewinnen diese Merkmale durch die Ideologie der nationalen $\mathrm{Ge}-$ meinschaft und nationalen Stärke.“ Faschistische Bewegungen „stellen also eine Form des Antikommunismus dar, die die rechtstaatlich-demokratischen Normen sprengt und tendenziell nach Vernichtung des Gegners trachtet ${ }^{19}$." Faschismus erscheint damit als Ultima ratio der Verteidigung des Bürgertums gegen die kommunistische Bedrohung. Dieser „nicht mehr parlamentarisch-rechtsstaatlich gebundene, und eben deswegen nicht mehr als ,bürgerlich' zu bezeichnende Antikommunismus" sei als „entscheidender und autonomer Impuls des Faschismus“ zu betrachten ${ }^{20}$. Den entscheidenden Unterschied zwischen totalitären Bewegungen einerseits und "Faschismus" anderseits sieht Wirsching vor allem in dem für den Totalitarismus „konstitutiven Merkmal der Ideologie“. Die faschistischen Bewegungen verfügten über kein „kohärentes ideologisches Orientierungssystem, das Geschichte, Gegenwart und Zukunft gleichermaßen erklärte, und ihnen fehlte der Wille, die bestehende Gesellschaftsformation radikal, gemäß einem ,bis in die Metaphysik hinein' fundierten neuen Wertsystem zu verändern ${ }^{21}$."

Die Ergebnisse dieser - letztlich auch auf einer nominalistischen Definition beruhenden - Faschismusanalyse regen zu mancherlei kritischen Anmerkungen an, die hier nicht im einzelnen vertieft werden sollen ${ }^{22}$. Evident ist aber, daß alle diese

17 Ebd., S. $518 f$.

18 Stanley G. Payne, Fascism. Comparison and Definition, Madison/Wisc. 1980; ders., A History of Fascism 1914-1945, London 1995.

19 Wirsching, Weltkrieg, S. 511 und S. 516.

20 Wirsching, Weltkrieg, S. 517.

21 Ebd., S. 524 f. Deswegen bezeichnet er den „hier entfalteten Faschismus-Begriff gewissermaßen nur als ,halb-totalitär ““, der vom „Typus der totalitären Bewegung streng unterschieden werden“ müsse. „Erst das Merkmal der Ideologie konstituiert den Typus vollständig [...] Neben dem Bolschewismus verfügte allein der Nationalsozialismus über eine umfassende, auf angeblichen Gesetzen beruhende Ideologie, die er dem in Deutschland besonders starken und ideologisch verselbständigten Kommunismus als Gegenideologie entgegenstellte. Eben dies macht seine totalitäre Differenz zu den faschistischen Bewegungen aus.“

22 Bezüglich der französischen Phänomene kann man z. B. bezweifeln, ob bestimmte, von Wirsching als "faschistisch“ deklarierte Gruppierungen tatsächlich alle drei „faschistischen Negationen“ erfüllten, und ob es wirklich zutrifft, daß der französische ,Faschismus“ einem "genuin antikommunistischen Impuls“ entsprang, oder ob er nicht auch andere, mindestens gleichgewichtige Antriebskräfte besaß. Außerdem läßt sich die These vom unmittelbaren, wie kommunizierende Röhren funktionierenden Zusammenhang zwischen der (im Vergleich zur KPD) geringeren Radikalität des PCF und der weniger „totalitären“ Ausprägung französischer „faschistischer“ Bewegungen kritisch hinterfragen; vgl. meine Rezension der Arbeit von Wirsching in: Militärgeschichtliche Mitteilungen 58 (1999), S. $628 \mathrm{f}$. 
nominalistischen Definitionen, die auf die Konstruktionen eines „faschistischen“ Idealtypus hinauslaufen, fragwürdig sind. Das Problem liegt in der Auswahl der Einzel-Elemente der jeweiligen idealtypischen Konstruktion. Erstens bleibt die Auswahl kontrovers, daher kommt es zu vielerlei unterschiedlichen Definitionen bzw. Idealtypus-Konstruktionen. Und zweitens läuft man bei einem solchen Verfahren Gefahr, die jeweilige historische Individualität zu verfehlen, indem man bestimmte Merkmale ohne eingehende Analyse für das jeweils Essentielle erklärt und zu konstitutiven Elementen des Idealtypus macht. Idealtypus-Konstruktionen mögen für Vergleiche legitim, nützlich, ja sogar unumgänglich sein. Aber es muß bei dem jetzigen Diskussionsstand doch für eine weitere Phase wissenschaftlicher Erkenntnisbemühungen auf der vertieften Erfassung der je nationalspezifischen Individualitäten bestanden werden, entweder als Korrektiv besagter idealtypischer Konstruktionen oder um methodische Alternativen zu ermöglichen. Daher sollen im Folgenden bestimmte Aspekte des französischen Rechtsextremismus in der Zwischenkriegszeit herausgearbeitet werden, die vielleicht eher als „substantielle“ Merkmale und als spezifische Eigentümlichkeiten genommen werden können.

II.

Bei der Analyse von gemeinhin als „faschistisch“ etikettierten „Bewegungen“ gehen wir von einem Ansatz aus, der erstens ihre politische und soziale Struktur in den Blick nimmt und zweitens ihre Funktion innerhalb des spezifischen Herrschaftssystems der französischen Dritten Republik untersucht. Mit einer Struktur- und Funktionsanalyse vor dem Hintergrund des nationalen republikanischparlamentarischen Systems soll deren Eigenart erfaßt werden. Ihre soziale Struktur wird in der Zusammensetzung der Kader und der Aktivisten erkennbar. Die politische Struktur wird greifbar in einer Analyse ihrer tatsächlich durchgeführten Politik, nicht so sehr in der jeweiligen Programmatik oder den Grundsatzdeklarationen. Sie werden bei unserem Ansatz zwar nicht unberücksichtigt bleiben, es wird ihnen aber doch geringeres Gewicht beigemessen. Meist dienten sie auch nur vordergründiger Propaganda. Obendrein wurde die Programmatik bei nicht wenigen dieser extremistischen Gruppierungen von radikalen Intellektuellen geprägt, die sich ihnen auf der Suche nach einem Resonanzboden, einer Massenbasis für ihre Ideen, zeitweilig angeschlossen hatten. Sie hatten gemeinhin keinen bedeutenden Einfluß auf die tatsächliche Politik der jeweiligen Gruppe ${ }^{23}$. Die $S y$ stem-Funktion dieser extremistischen Gruppen wird in ibrem Stellenwert innerhalb des politisch-sozialen Systems der Dritten Republik erkennbar. Dabei ist vor

23 Hieraus folgt, daß sich die "Intellos“ nach einer gewissen Zeit enttäuscht von der betreffenden Gruppierung abwandten oder ausgeschlossen wurden. Sie wanderten so durch mehrere dieser „Bewegungen“. So engagierte sich Drieu la Rochelle z. B. zunächst in Bergérys Front Commun, dann glaubte er in Jacques Doriots PPF die Plattform zur Verbreitung seiner Ideen gefunden zu haben, schließlich trennte er sich auch von dieser. Am Ende faszinierte ihn der stalinistische Kommunismus. Ähnlich war der politische "trajet“ von Jean Pierre Maxence, der zeitweilig in Cotys S.F. aktiv war, dann zu Doriot ging und später in Vichy aktiv war. Ähnliches ließe sich auch bei Maulnier, Fabre-Luce u. a. feststellen. 
allem der Wandel zu berücksichtigen, dem dieses System gerade in der Kriegsund Nachkriegszeit ausgesetzt war.

Das republikanisch-parlamentarische System Frankreichs läßt sich am besten mit einem Strukturmodell erfassen, dessen zentrale Elemente mit den Begriffen „Blockierte Gesellschaft" und „republikanische Herrschaftssynthese“ beschrieben werden können ${ }^{24}$. Im folgenden soll exemplarisch und skizzenhaft aufgezeigt werden, wie man sich mit einem solchen funktionalen und strukturellen Zugriff den historischen Erscheinungen nähern könnte ${ }^{25}$.

Die „blockierte Gesellschaft" bildete die sozio-ökonomische Grundlage des politischen Systems der Dritten Republik. Ihre spezifische Eigenart wurde erstens durch jenen für Frankreich typischen Dualismus bestimmt, einem Nebeneinander von fortgeschrittenen und vor-industriellen Sozialgruppen und Wirtschaftsbereichen; und zweitens von deren „prekärer Balance“, die der Wirtschaft und Gesellschaft Frankreichs eine gewisse relative Stabilität verlieh, deren Kehrseite allerdings eine gehemmte bzw. verhinderte Modernisierung war. Den politischen Kern des Systems bildete die "republikanische Synthese“. Sie bezeichnet die Verbindung jener Teile der politisch wie wirtschaftlich liberal eingestellten Bourgeoisie mit den demokratischen Mittelschichten, die sich auf der Grundlage eines umfassenden Konsensus über die tragenden politischen und sozialen Prinzipien der Republik zur Ausübung der politischen und sozialen Herrschaft zusammengefunden hatten. Dieses Arrangement zwischen liberaler Bourgeoisie und demokratischen Mittelschichten war im Verlauf der Auseinandersetzung mit jenen konservativen Kräften der Großbourgeoisie entstanden, die sich nach 1871 mit Teilen von Adel, Kirche und Armeekreisen dem laizistisch-liberalen Ausbau der Republik widersetzt hatten. Die liberale Bourgeoisie, die aus den freien Berufen stammte oder in Handel und Gewerbe tätig war, und der auch die Wirtschaftsbourgeoisie (Schwerindustrie und Banken) zuzurechnen ist, wurde politisch überwiegend von den Gruppierungen der rechten Mitte bis zur gemäßigten Rechten repräsentiert. Die Mittelschichten in Stadt und Land fanden ihre politische Repräsentanz vornehmlich bei den Gruppierungen der „Radicaux“26. Das radikal-liberale Bündnis war somit der politische Ausdruck der „republikanischen Synthese“.

24 Dieses Modell beruht auf einer Weiterentwicklung der von Stanley Hoffmann und Michel Crozier vorgelegten Auffassung, vgl. Stanley Hoffmann, Paradoxes of the French Political Community, in: ders. u. a. (Hrsg.), In Search of France, Cambridge/Mass. 1963; und Michel Crozier, The Stalled Society, New York 1973; wichtig für die modellhafte Weiterentwicklung und Anpassung: Roland A. Höhne, Faktoren des außenpolitischen Meinungs- und Willensbildungsprozesses innerhalb der gemäßigten Rechten Frankreichs in den Jahren 1934-36, Diss. Berlin 1968; und ders., Die strukturellen Bedingungen der französischen Außenpolitik, in: Soz.wiss. Forschungen, Arbeitsbericht des Zentralinstituts 6 der Freien Universität Berlin 1972-1975, im Auftrag des Institutsrates zusammengestellt und bearbeitet von Ute Schmidt, München 1975.

25 Ausführlicher vorgestellt und erprobt wurde dieser Ansatz an einigen extremistischen Bewegungen in: Klaus-Jürgen Müller, Protest - Modernisierung - Integration. Bemerkungen zum Problem faschistischer Phänomene in Frankreich 1924-1934, in: Francia 8 (1981), S. 465-523.

26 Vgl. Serge Berstein, Histoire du Parti Radical, 2 Bde., Paris 1980-82. Sehr instruktiv auch die Beiträge in: Georges Lavau/Gérard Grunberg/Nonna Meyer (Hrsg.), L'Univers Politique des classes moyennes, Paris 1983; knappe Zusammenfassung bei Nonna Meyer, Les classes moyennes dans la vie politique française, 1919-1939, in: Horst Möller u.a. (Hrsg.), Gefährdete Mitte? Mittelschichten und politische Kultur zwischen den Weltkriegen: Italien, Frankreich und Deutschland, Sigmaringen 1993 (Beihefte der Francia 29), S. 83-93. 
Die konkrete Herrschaftsausübung der republikanischen Synthese erfolgte über ein politisches System, dessen Charakteristikum das „Régime des Assemblées“, die Dominanz des Parlamentes, war. Die sozio-ökonomischen Interessen wurden durch den parlamentarischen Mechanismus in die politisch-administrative Entscheidungssphäre vermittelt. Über das Parlament fanden die sozio-ökonomischen Interessengegensätze eine institutionalisierte politische Austragungsmöglichkeit, wobei die Regierung quasi der Arbeitsausschuß des Parlamentes war. Diese Interessentransmission erklärt die häufigen Kabinettswechsel, deren volatile Mehrheiten Ausdruck von sich ad-hoc bildenden Interessenkoalitionen quer durch unterschiedliche politisch-parlamentarische Gruppierungen hindurch waren. Die oft mit negativem Unterton als politische Zersplitterung bezeichnete Fragmentierung der Kräfte von der linken Mitte bis zur gemäßigten Rechten war unter diesem Aspekt geradezu eine wesentliche Voraussetzung für die flexible Wahrung vielfältiger sozio-ökonomischer Interessen im politischen Entscheidungsbereich von Legislative und Exekutive. Dieses System der Transmission sozio-ökonomischer Interessen in die politische Entscheidungssphäre hatte sich seit Ende der siebziger Jahre des 19. Jahrhunderts allmählich eingespielt und war von den Beteiligten voll internalisiert worden. Jene die liberal-demokratische Republik ablehnenden Kräfte auf der Linken (Sozialisten, Anarcho-Syndikalisten) wie auf der extremen Rechten (Monarchisten, intransigente Katholiken) waren in diesem Herrschaftssystem nicht vertreten.

Der Unterschied zu Deutschland ist überdeutlich: dort erfolgte bis Ende 1918 diese Interessentransmission nicht direkt über Parteien in das Parlament, das keine verfassungsmäßige Befugnis über die Exekutive besaß, sondern vor allem über extra-konstitutionelle Einfluß- und Interessengruppen unmittelbar in die vom Parlament weitestgehend unabhängige Regierung und Verwaltung. Das erklärt einerseits das Entstehen von einflußmächtigen Interessen-Verbänden ${ }^{27}$, anderseits später in der Republik von Weimar die geringe Akzeptanz der ungewohnten (noch dazu aus der Niederlage entstandenen) parlamentarischen Demokra$t^{2} e^{28}$. Vor dem Hintergrund einer historisch gewachsenen und positiv besetzten autoritären Staatsstruktur sowie eines machtvollen Verbandswesens war der Antiparlamentarismus in Deutschland unmittelbarer Ausdruck grundsätzlicher Ablehnung von Demokratie und Parlamentarismus. Solche prinzipielle Parlamentsfeindschaft gab es in Frankreich auch, vor allem bei den nicht in das Herrschaftssystem integrierten bzw. das Herrschaftssystem ablehnenden Kräften, aber sehr weitgehend und viel häufiger war das, was auf den ersten Blick (vor allem in deutscher Perspektive) als grundsätzlicher Antiparlamentarismus erscheinen mochte, nur eine in oft heftige Ausdrucksformen gekleidete Parlamentskritik. Sie trat entweder als Forderung nach Staatsreform auf, oder - spezifischer - als Forderung nach einer anderen, „besseren“ Zusammensetzung des Parlamentes bzw. nach

27 Zwischen 1880 und 1900 stieg die Zahl der Interessenverbände in Deutschland von ca. 150 auf über 500. Der obrigkeitstaatlichen Exekutive stand damit eine hochgradig selbstorganisierte Gesellschaft gegenüber.

28 Die kurze Unsicherheitsphase 1918-19 blieb Episode. In der damaligen revolutionären Lage waren die Verbände schwach und daher bereit, sich auf die Seite der parlamentarischen Kräfte zu schlagen, um die Etablierung eines Räteherrschaftssystems zu vermeiden. 
Austausch parlamentarischer Elitegruppen. Jedenfalls ist für die zutreffende Erfassung der französischen Erscheinungen an diesem Punkt eine genaue Unterscheidung notwendig. Nur hier wie dort Antiparlamentarismus festzustellen, genügt nicht, verzerrt vielmehr den Vergleich.

Für die weitere Entwicklung dieses republikanisch-parlamentarischen Systems waren in unserem Zusammenhang drei Momente von besonderer Bedeutung: „Erstens hatten seit dem Ersten Weltkrieg wesentliche Teile jenes der laizistischliberalen Republik bisher ablehnend gegenüberstehenden konservativen Bürgertums und der traditionellen Katholiken begonnen, sich allmählich dem republikanischen Herrschaftssystem anzunähern “29. Der Öffnungsprozeß - der Ralliement catholique und der Ralliement conservateur - bot diesen Kräften einerseits Partizipationschancen, anderseits erweiterte auch die Amalgamierung von Gruppen der konservativen Rechten und des konservativen Katholizismus die „republikanische Synthese ${ }^{30}$. Diese hatte damit ihre Integrationskraft bewiesen. Genau dies fand in Deutschland nach 1918 eben nicht statt. Breite Kreise der konservativen Rechten, die das politisch-soziale Systems des Kaiserreiches getragen hatten, lehnten die Republik von Weimar nachhaltig ab. Zweitens traten in Frankreich im Gefolge des Ersten Weltkriegs bestimmte ökonomische und soziale Veränderungen auf, die zu einer spürbaren Verschärfung der gesellschaftlichen Gegensätze führten. Seit Mitte der 20er Jahre kam es zu einem bemerkenswerten Aufschwung moderner Wachstumsindustrien wie der Großchemie, der Elektroindustrie und Ölwirtschaft, des Automobilbaus sowie bestimmter Bereiche des Dienstleistungssektors, unter anderem des Banken- und Versicherungswesens. Ein solcher industriewirtschaftlicher Modernisierungsschub hatte sich in Deutschland (mit Ausnahme der Automobil-Industrie) schon zwei Jahrzehnte zuvor ereignet, und zwar noch intensiver und tiefgreifender. Drittens hatten diese ökonomischen Veränderungen in Frankreich unmittelbare soziale Auswirkungen. Insbesondere die für den "neuen Mittelstand" konstitutiven Sozialgruppen, vor allem kaufmännische und technische Berufe, aber auch die Angehörigen moderner staatlicher wie privater Dienstleistungsbranchen gewannen nunmehr neben den Industriearbeitern stärkeres Gewicht. Diese sozio-ökonomischen Veränderungen beeinflußten in hohem Maße die Reaktion der französischen Politik auf die schwerwiegenden Herausforderungen, welche die Bewältigung der Kriegsfolgeprobleme für Frankreich bedeutete. Das wurde vor allem im Bereich der Finanz-, Steuer- und Geldpolitik deutlich.

Jene erwähnten drei Momente - erstens der doppelte „Ralliement“ von konservativen und katholischen Kräften, zweitens die ökonomischen Veränderungen im

29 Dies hat sicher zur Schwächung der A.F. beigetragen, die in der Zwischenkriegszeit eine zunehmend geringere Rolle spielte. Sie wird daher hier nicht behandelt, obgleich Nolte in ihr den Prototyp des „Faschismus" sieht. Vgl. auch Eugen Weber, Action Française. Royalism and Reaction in Twentieth Century France, Stanford 1962; Edward R. Tannenbaum, The Action Française. Diehard reactionaries in Twentieth Century France, New York 1962; Michel Winock, L'Action Française, in: ders., Histoire de l'extrême droite en France, Paris 1993, S. 125-156. Allgemein vgl. die einschlägigen Abschnitte in: Sirinelli (Hrsg.), Histoire des Droites en France, Bd 1.

30 Vgl. hierzu die knappen Überblicke von Rémond, Les Droites, S. $194 \mathrm{ff}$. und Philippe Bernard, La fin d'un monde 1914-1929, Paris 1979; und ders./André Latreille, Histoire du Catholicisme en France, Bd. 1: La Période Contemporaine, Paris 1962; sowie die ausführlichen bibliographischen Angaben in: Sirinelli (Hrsg.), Histoires des Droites en France, Bd. 3, S. 688-695. 
industriewirtschaftlichen Bereich sowie drittens die daraus resultierenden gesellschaftlichen Wandlungen - hatten nicht nur allgemeinen Einfluß auf die weitere Entwicklung des politisch-sozialen Systems, sondern sie standen auch in unmittelbarem Zusammenhang mit den von uns nunmehr zu betrachtenden politischen Erscheinungen innerhalb des Spektrums der französischen Rechten. In diesem Rahmen traten spezifische, neuartige Phänomene auf, bei denen es überaus fraglich ist, ob man sie mit irgendeinem Faschismus-Modell erfassen kann.

\section{III.}

Seit Mitte der zwanziger Jahre erschienen in Frankreich Gruppierungen, die schon von Zeitgenossen, insbesondere von politischen Gegnern als „faschistisch“ bezeichnet wurden. Innerhalb dieser "First wave of French Fascism" - wie Robert J. Soucy sie genannt hat ${ }^{31}$ - war die nach Zahl und politischem Gewicht fraglos bedeutendste Gruppe bis etwa 1932/34 die "Ligue des Jeunesses Patriotes“ (J.P.) ${ }^{32}$. Ein Teil der Forschung bezeichnet sie als „faschistisch“, während andere Autoren sie nur als Neuauflage der klassischen Ligen in neuem Gewande ansehen ${ }^{33}$. Bei ihrer historischen Einordnung und Erklärung bestehen also weder Einhelligkeit noch Klarheit. Um hier weiter zu kommen, untersuchen wir zunächst $U m s t a ̈ n d e$ und Ursachen ibrer Entstehung.

In der einschlägigen Literatur wird die Gründung der J.P. als bürgerliche Schreckreaktion auf den Wahlsieg des Cartel des Gauches vom 11. Mai 1924 und auf die machtvolle Demonstration der Linken anläßlich der Überführung der sterblichen Überreste von Jean Jaurès in das Pantheon (28. Oktober 1924) angesehen: „Aus der Erregung, die daraus resultierte, gingen vor allem die Jeunesses $\mathrm{Pa}$ triotes hervor, welche von dem Pariser Abgeordneten Pierre Taittinger gegründet wurden34." Ernst Nolte sieht daher in ihnen einen Ausdruck des bürgerlichen Antikommunismus, der für ihn eine der Ursachen für die Entstehung eines „französischen Faschismus" der Zwischenkriegszeit war. So sehen es auch die Untersu-

31 Robert J. Soucy, French Fascism. The First Wave, 1924-1933, New Haven/London 1986.

$32 \mathrm{Zu}$ den Jeunesses Patriotes vgl. außer den unter Anm. 11 und 28 genannten Arbeiten von Pierre Milza und Robert J. Soucy, die Studie von Jean Philippet, Les Jeunesses Patriotes et Pierre Taittinger 1924-1940, Mémoire I.E.P., Paris 1967 (unveröffentlicht), der vornehmlich die einschlägige Publizistik und einige private Archivalien auswertet; dagegen beruhen die Arbeiten von Cathérine Olanié-LeGac, Les Jeunesses Patriotes 1924-28, Mémoire de Maîtrise, Université de Paris IV, 1978; und Müller, Protest, S. 471-483; sowie ders., Die französische Rechte und der Faschismus in Frankreich 1924-1932, in: Dirk Stegmann/Bernd-Jürgen Wendt/Peter-Christian Witt (Hrsg.), Industrielle Gesellschaft und politisches Herrschaftssystem, Beiträge zur politischen Sozialgeschichte, Bonn 1978, S. 413-430, auf den in den Archives Nationales, Paris (AN), vorhandenen Materialien der Serie F7 (Police Générale). Für die folgenden Abschnitte stützen wir uns vornehmlich auf die Bestände Nr. 13.232 (1925-32 „Notes sur 1'activité politique«), 13233 (Präfektur-Berichte 1926), 13234 (Präfektur-Berichte 1927/28), 13235 (»Activités J. P. 1928-1932«) sowie 12952-12958 (Allgemeine Lageberichte "Notes Jean« 1924-1931).

33 Wie etwa Milza, Les Fascismes, S. 259 im Gefolge von Rémond; vgl. auch Philippet, Taittinger, passim und Olanié-LeGac, Les Jeunesses Patriotes, S. 3-21; sowie Plumyène/Lasierra, Les Fascismes Français, S. $28 \mathrm{ff}$; und Machefer, Ligues et Fascisme en France, S. $10 \mathrm{ff}$.

34 Nolte, Die faschistischen Bewegungen, S. $294 \mathrm{f}$. 
chungen von Robert Soucy und Andreas Wirsching35. Diese These beruht lediglich auf einer prima vista plausiblen Zusammenschau von ungefähr gleichzeitig auftretenden Ereignissen. Die Reaktionsthese ist jedoch erstens nicht überzeugend, weil - wie die Quellen ${ }^{36}$ zeigen - die Initiative zur Gründung einer solchen politischen Gruppierung schon vor dem damals als spektakulär und von der Rechten als katastrophal empfundenen Wahlsieg der Linken erfolgte. Zweitens zeigt eine eingehende Analyse der Umstände ihrer Entstehung, daß sie in einem weit umfassenderen Kontext zu sehen ist, als nur in dem zufälligen zeitlichen $\mathrm{Zu}$ sammentreffen mit dem linken Wahlsieg. Zunächst ist darauf zu verweisen, daß schon Ende 1923 jüngere Politiker der konservativen Rechten, die meist der „Génération du feu", der Generation der Kriegsteilnehmer, angehörten, sowie Aktivisten der Patriotenliga den Gedanken erwogen hatten, man müsse, ungeachtet aller unterschiedlichen Tendenzen auf der politischen Rechten, eine große konservativnationale Sammlungsbewegung ins Leben rufen. Die unübersehbaren Auflösungserscheinungen der Parlamentsmehrheit des „Bloc National“ sowie Tendenzen innerhalb der „Radicaux“, Wahlarrangements mit den Sozialisten zu erwägen, waren angesichts der bevorstehenden Wahlen der aktuelle Anlaß. Viel bedeutsamer als diese für den Augenblick wenig folgenreiche Aktion war jedoch, daß solche Initiativen weder ein isoliertes noch ein situationsbedingtes Phänomen darstellten. Sie waren mehr als bloße Bemühungen um eine zeitlich begrenzte Wahlallianz. Jene Persönlichkeiten, die sich im April 1924 zusammenfanden, hatten über alle aktuellen wahltaktischen Erwägungen hinaus ein wesentlich anspruchsvolleres Ziel ins Auge gefaßt: die politische Neustrukturierung und Konzentration der gesamten Rechten.

In dieser Hinsicht gab es aufschlußreiche Vorläufer. Bereits 1919 hatten Politiker der republikanischen Rechten den „Parti Républicain de Réorganisation $\mathrm{Na}$ tionale “ 37 begründet, dem Deputierte des „Bloc National“ angehörten. In seinen Reihen waren vor allem Persönlichkeiten zu finden, die später zur Führungsequipe der J.P. oder zu deren Sympathisanten gehörten ${ }^{38}$. Die neue Partei umfaßte unterschiedliche Elemente aus dem gesamten rechten Spektrum, etwa aus dem Umkreis des sozialen Katholizismus oder der konservativ-nationalistischen „Fédération Républicaine“ sowie bonapartistische und republikanische Nationalisten. Zu den Mitbegründern der Partei gehörte vor allem der Abgeordnete von Charente Inf., Pierre Taittinger, später der dynamische Führer der J.P. ${ }^{39}$ Taittinger, ein Repräsentant der Kriegsgeneration, hatte seit seiner Wahl 1919 immer wieder auf die Notwendigkeiten einer "unité des nationaux“, einer politisch-organisato-

35 Soucy, French Fascism, S. 39; und Wirsching, Weltkrieg, S. 280ff. (letzterer mit allerdings mancherlei Einschränkungen bei grundsätzlichem Festhalten an „Faschismus“-Qualifizierung).

36 AN F7-13.232 (vor allem den zusammenfassenden Rückblick der Polizei vom Mai 1925) und 13.241; vgl. Philippet, Taittinger, S. 8 ff.; und Olanié-LeGac, Les Jeunesses Patriotes, S. 3 ff.

37 Vgl. Henry Coston, Dictionnaire de la Politique Française, Bd. 1, Paris 1967, S. 814.

38 Vgl. Henry Coston, Dictionnaire de la Politique Française, Bd. 2, Paris 1972, S. 684 (de Warren), S. 390 (Gaston Le Provost de Launay) sowie Coston, Dictionnaire, Bd. 1, S. 97 (Joseph Barthélémy).

39 Über Taittinger vgl. insbesondere Olanié-LeGac, Les Jeunesses Patriotes, S. 22 ff.; Philippet, Taittinger, S. $10 \mathrm{ff}$.; und Coston, Dictionnaire, Bd. 1, S. $998 \mathrm{f}$. und S. $569 \mathrm{f}$.; sowie Weber, Action Française, S. 155. Polizeiberichte über Taittinger unter anderem in: AN F7-13.232 (vom 4.3.1926 und 12. 7. 1926). 
rischen Zusammenfassung der verschiedenen Gruppierungen und Tendenzen der politisch wie organisatorisch traditionell zersplitterten französischen Rechten hingewiesen. Er wollte die nationalistische und konservative "droite ralliée“, die sich inzwischen mit der Republik ausgesöhnt hatte, mit den Gruppierungen der liberalen Rechten vereinen. Mit diesem Gedanken stand er nicht allein.

Die Idee einer umfassenden Konzentration aller Kräfte der gesamten Rechten wurde damals von nicht wenigen Anhängern dieser „famille politique“ aufgegrif$\mathrm{fen}^{40}$. Anfang 1922 tauchten z. B. in konservativen Zeitungen Meldungen auf, welche die Gründung einer „Action Nationale Républicaine“ (ANR) ankündigten. Ein Kommentator bemerkte dazu, die ANR solle eine neue Partei darstellen, die als Repräsentation der vereinigten Rechten auftreten wolle. Initiator war François Arago, Vizepräsident der Kammer und einer der parlamentarischen Führer der die Regierungsmehrheit mittragenden rechtskonservativen „Entente Républicaine Démocratique“. Von antiparlamentarischen, das republikanisch-demokratische System in Frage stellenden "faschistischen“ Tendenzen kann also nicht die Rede sein. Hintergrund dieser Initiativen war vielmehr das allmähliche Zerbröckeln der parlamentarischen Majorität des „Bloc National“. Die ANR steht somit in der Reihe von Versuchen, durch politische Konzentration die Position der gesamten Rechten gegenüber Mitte-Links-Tendenzen zu konsolidieren. Diese Tendenz verstärkte sich, je mehr der bürgerliche Konsensus unter den Problemen der Kriegsfolgen zu zerbröckeln drohte.

Als Zwischenergebnis kann man also feststellen: Die geschilderten Initiativen sind letztlich als Symptome für einen historischen Umstrukturierungsprozeß innerhalb der französischen Rechten anzusehen ${ }^{41}$. Erstens hat es seit 1919 beständige Bemühungen gegeben, die republikanisch eingestellten Kräfte der konservativen Rechten mit der liberalen Rechten, welche die republikanische Herrschaftssynthese repräsentierte, in einer großen rechts-republikanischen Sammelbewegung zusammenzufassen. Damit sollte die überkommene Fraktionierung der politischen Rechten überwunden werden, nachdem sich deren interne ideologische Trennlinien seit 1914 immer mehr verwischt hatten. Solche Sammlungstendenzen waren daher Ausdruck des "ralliement républicain", des Amalgamierungsprozesses wesentlicher Teile der konservativen Bourgeoisie mit dem politischen System der Dritten Republik. Zweitens waren sie Ausdruck einer Modernisierungstendenz auf der Rechten. Die Möglichkeit einer Links-Öffnung des bislang vom Konsensus zwischen liberalen Rechten und jakobinisch-demokratischen Radicaux getragenen republikanischen Systems war damals nicht mehr auszuschließen. Angesichts einer solchen Schwerpunktverlagerung des bisherigen Systemspektrums zur linken Mitte durch ein Zusammengehen der Radicaux mit Teilen der Sozialisten im Cartel des Gauches lag der Gedanke nahe, einen solide strukturierten Rechtsblock zu schaffen, der die verschiedenen Gruppierungen der gesamten Rechten zusammenfaßte. Dieser Block hätte wahlarithmetisch die Chance gehabt, jegliche Links-Öffnung der jakobinisch-liberalen Mitte unmöglich zu ma-

40 Hierzu und zum folgenden vgl. die Darstellung und die Quellenbelege bei Müller, Protest, S. $474 \mathrm{f}$.

41 Daß solche Tendenzen auch - aber nicht ausschließlich - mit dem Wahlsieg der Linken 1924 zu tun haben, soll damit nicht geleugnet werden. Die Gründung der Fédération Nationale Catholique im August 1924 und der Ligue Nationale 1927 durch Millerand sind hier zu nennen. 
chen. Und auf diese Weise hätte der unter dem Druck der Kriegsfolgelasten zerbröckelnde bürgerliche Konsensus erhalten bleiben können. Doch dazu bedurfte die Rechte einer modernen Parteiorganisation statt der bisherigen lockeren Strukturen, die eine konstante und kohärente Willensbildung verhinderten.

Die in der Form an die ligistische Tradition anknüpfenden J.P. waren bezeichnender Ausdruck dieser Entwicklung. Sie waren also weit mehr als bloß eine bürgerliche Schreckreaktion auf den Wahlsieg des Cartel des Gauches. Sie standen vielmehr in einer Reihe analoger Erscheinungen seit 1919, die alle tendenziell darauf ausgerichtet waren, die verschiedenen Kräfte der liberalen und der konservativen Rechten in das republikanische System zu integrieren und zu einer bedeutenden politischen Kraft zu machen. So sollte die republikanische Synthese auf breiter rechter Basis neu fundiert werden. Dazu war eine umfassende politische Mobilisierung notwendig. Sie erforderte neue Formen der politischen Aktion. Die ligistischen Traditionen boten hier einen Ansatzpunkt. Aber man sollte die „Mobilisierung der Straße“ - wie man es polemisch nennen könnte - nicht als „Faschismus-Indiz" mißverstehen. Die Linke setzte ebenfalls auf Massenmobilisierung. Der Massenaufmarsch anläßlich der Überführung des Leichnams von Jaurès zeigte dies. Hier handelt es sich insgesamt um Formveränderungen der Politik in einer Zeit der beginnenden Massendemokratie, welche die überkommene Form der Honoratiorenpolitik ablöste. Die Gründung der J.P. war daher sowohl Konsequenz des Ralliement der konservativen Rechten an das republikanische System als auch Ausdruck einer Modernisierung nicht nur des gesamten rechten Spektrums, sondern des politischen Lebens überhaupt.

Dieser Befund wird durch die Ergebnisse einer Analyse der konkreten Politik der J.P. bestätigt ${ }^{42}$. Dabei sind zwei verschiedene Ebenen zu unterscheiden. Auf der einen Ebene, jener der außerparlamentarischen Aktivitäten, ging es primär um Mobilisierung. Da zwischen 1919 und 1924 sämtliche Initiativen zur Sammlung aller system-konformen rechten Kräfte im Sande verlaufen waren, sah sich die Führungsequipe unter Taittinger vor die Aufgabe gestellt, durch eine breit angelegte Mobilisierung die vorhandenen Hindernisse zu überwinden und zu einer effektiven Integration zu kommen. Derartige Mobilisierungs- und Integrationsbemühungen erfolgten mit unterschiedlichen Methoden. Im Vordergrund der Szene standen der schon von zeitgenössischen Betrachtern konstatierte militante Antikommunismus und die paramilitärische Organisationsform - beide in der einschlägigen Literatur oft als Faschismusindikatoren hervorgehoben ${ }^{43}$. Konkret äußerte sich diese Mobilisierungs- und Integrationsstrategie in heftigen politischen Attacken sowie spektakulären, wohlorganisierten Manifestationen, aber auch in tätlichen Auseinandersetzungen mit kommunistischen und sozialistischen

42 Zum folgenden vgl. die ausführliche Analyse bei Müller, Protest, S. 474-483 und die dortigen Quellenbelege.

${ }^{43}$ Wirsching hebt auf Grund seines Vergleichsschemas Deutschland - Frankreich fast exklusiv auf den Faktor "Antikommunismus" ab. Im Gesamtzusammenhang ist dies gewiß nicht falsch. Der Antikommunismus war seit 1917/18 ein zunehmend wichtiger Faktor, darf aber nicht als einzige Triebkraft der Entwicklung verabsolutiert werden, insbesondere nicht für das Frankreich der zwanziger Jahre. Man muß bei den entsprechenden Quellenaussagen sorgfältig unterscheiden, was propagandistisches Mobilisierungsargument oder zielgerichtete politisch-programmatische Aussage ist. 
Gruppen, bei denen sich besonders die studentische Organisation der J.P., die „Phalanges universitaires“, hervortaten, sowie in schrillen, mit großem Propaganda-Aufwand artikulierten Warnungen vor einer aufziehenden kommunistischen Gefahr. Von dieser konnte indessen keine Rede sein. Der Slogan von der bolschewistischen Gefahr war nur eine polemische Chiffre für die Möglichkeit einer sozialistisch-radikalen Entente, für den drohenden Abbau von Privilegien oder für die mögliche Einführung eines gerechteren Steuersystems. Hier wurden schlichtweg sozio-ökonomische Bedrohungsvorstellungen ausgenutzt oder sogar erst suggeriert. Diese Propaganda war ebenso Ausdruck einer Mobilisierungsund Integrationsstrategie der umfassenden rechten Sammlungspolitik wie die militante, oft in pseudomilitärischen Formen ${ }^{44}$ erfolgende Selbstdarstellung der J.P. auf Straßen und in Versammlungssälen.

Auf einer zweiten Ebene, gleichsam hinter dem Vordergrundgetöse außerparlamentarischer Polit-Aktivitäten ${ }^{45}$, befleißigte sich die Führungsequipe um Taittinger einer ganz und gar system-konformen konservativ-republikanischen Politik. Jene ultra-rechten, extremistischen und system-kritischen Kräfte, die mit einer derartigen republikanischen Politik nicht einverstanden waren, wurden ausgeschlossen oder zogen sich von selbst zurück. Aufschlußreich waren die von den extremistischen Kräften gegenüber Taittinger und dessen Anhängern erhobenen Vorwürfe, sie seien „Politiker", wohingegen der Ausschluß der Extremisten mit der Begründung erfolgte, sie seien „Faschisten “46. So spiegeln auch die Veränderungen in der Führung der J.P. den Trend zu einer republikanischen system-konformen Politik wider ${ }^{47}$. Der von enttäuschten Anhängern erhobene Vorwurf des „électo-

44 Die paramilitärische Erscheinungsform, die oft als Faschismus-Indikator dient, gehört eher in den umfassenden Bereich der Formveränderung der Politik nach dem Ersten Weltkrieg. Man muß sich stets vor Augen halten, daß in den kriegführenden Ländern viele Millionen Männer erstmals über lange Jahre in militärischem Milieu gelebt haben. Es wäre seltsam, wenn viele dieser Männer (so sie aus dem Kriegserlebnis heraus nicht zu Pazifisten geworden waren) die militärischen Organisationsformen - zu Recht oder Unrecht - nicht als (vermeintlich) effektiver internalisiert hätten. Vom „Stahlhelm“ über Reichsbanner bis hin zu Parteiorganisationen des Zentrums waren pseudo-militärische Formen damals ebenso üblich wie in den Organisationen der Anciens Combattants in Frankreich, deren demokratisch-republikanische Loyalität Antoine Prost überzeugend nachgewiesen hat. Davon zu unterscheiden sind indessen die - wie Andreas Wirsching gezeigt hat - tendenziell auf Vernichtung des Gegners abhebenden terroristischen Parteitruppen wie die SA und der Rote Frontkämpferbund, die mit Recht als para-militärisch zu qualifizieren sind. Diese von uns hervorgehobene Unterscheidung zwischen den beiden auf den ersten Blick formal identischen, dennoch aber inhaltlich grundverschiedenen Erscheinungen ist unbedingt zu beachten.

45 Man darf nicht aus der martialischen rhetorischen Selbstdarstellung dieser Gruppe auf deren „totalitären Charakter" schließen. Solche ideologiekritisch angesetzte Methode nimmt die Selbstdarstellung für bare Münze und hält für totalitäres Symptom, was bloß neuartiger Politikstil - Formveränderung der Politik - war. Vgl. das Zitat und die entsprechende Interpretation bei Wirsching, Weltkrieg, S. 285.

46 AN F7-1323 Bericht vom 19. 11. 1925. Vgl. auch Maurras’ Angriff: „Les Jeunesses Patriotes [...] sont devenues en fait les Jeunesses Patriotes républicaines, parlementaires, ministérielles, électorales. C'est le titre complet!“ Taittinger antwortete ebenso eindeutig: „Nous n'avons jamais envisagé la déstruction du régime. Nous respectons infiniment ce que fut. Loin de vouloir déchirer les plus belles pages de notre histoire, nous pensons que tous les hommes de gouvernement devraient y apprendre la manière de gouverner [...] Nous n'avons jamais envisagé la suppression totale du Parlement [...]" (L'Action vom 11. 3. 1929 und Le National vom 17. 3. 1929).

47 Vgl. auch die ironisch-paradoxe Antwort eines J.P.-Anhängers auf entsprechende Vorwürfe bei William D. Irvine, French Conservatism in Crisis. The Republican Federation of France in the Thirties, Baton Rouge/Louis. 1979; S. 105: die J.P. repräsentierten, wenn man sie schon faschistisch nennen wolle, auf jeden Fall einen „republikanische[n] Faschismus“. 
ralisme" verweist auf die Grundrichtung dieser Politik: sie war eindeutig republikanisch-parlamentarisch ausgerichtet. Es kann bei der Politik der J.P. gar keine Rede sein von Antiparlamentarismus und Antirepublikanismus, mögen auch einem Teil der Anhängerschaft derartige Tendenzen nicht fremd gewesen sein. Diese Anhänger haben aber nie die Politik der J.P. bestimmen können, wurden vielmehr alsbald aus der Bewegung herausgedrängt. Die J.P. haben jedenfalls in den Jahren 1924-1926 bei Nachwahlen schwerpunktmäßig Kandidaten der republikanischkonservativen oder liberal-konservativen Richtung unterstützt, u.a. Reynaud, de Kérillis und Millerand. Zum Wahlsieg der Rechten 1928 trug nicht zuletzt ihre Kooperation mit der „Fédération Républicaine“/UDR bei: Das war eine klassische Politik des "ralliement républicain“ rechtskonservativer Kräfte. Durch diese Politik konnte die parlamentarische Basis der Regierung der „Union Nationale“ auf Kosten der bisherigen radikalen Koalitionspartner nach rechts verbreitert werden. In Nachwahlen sowie bei den Munizipalwahlen setzte Taittinger diese Politik der "nationalen Sammlung“ und des parlamentarischen „Ralliement" der konservativen Rechten fort. Die J.P. schienen ihrem wichtigsten Ziel, einer breiten republikanischen Einheitsfront aller Rechten, allmählich näher zu kommen.

Der Rücktritt der radikalen Minister aus dem von den J.P. unterstützen Kabinett Poincaré im Oktober 1928 wurde von der J.P.-Führung heftig kritisiert, obwohl sie zuvor deren Gewicht innerhalb der Regierungskoalition bekämpft und schließlich in den Wahlen erfolgreich reduziert hatte. Gerade dieser Vorgang ist überaus aufschlußreich: es ging eben gar nicht um eine Eliminierung der „Radicaux" und um eine exklusive Alleinherrschaft der Rechten, die letztlich die Zerstörung der "republikanischen Synthese“ bedeutet hätte. Es ging einfach darum, die Radicaux an einer Linksöffnung zu hindern durch eine breitestmögliche Fundierung der „Union-Nationale“-Majorität in einer Regierung mit den (dann minoritären) Radicaux. Auf dem Kongreß der J.P. in Marseille 1930 trat Taittinger daher für die Bildung einer großen bürgerlichen Partei zur politischen Unterstützung Tardieus ein. Eine solche würde fortan der gesamten Rechten die Regierungsführung gestatten, ohne sie ständig in brüchige Koalitionen mit undisziplinierten Teilen der Rechten und mit den nicht weniger volatilen „Radicaux“ zu zwingen und so einer permanenten Gefährdung auszusetzen. Konkret hieß dies: eine Majorität sollte geschaffen werden, die sich von Rechts bis zur Mitte erstreckte, also auch möglichst große Teile der „Radicaux“ miteinschloß, in der die Rechte jedoch durch ihre Kohärenz und ihre Zahl so stark war, daß den radikalen Elementen der Mitte das Manöver eines Abschwenkens nach links nicht mehr möglich war. Das, nicht mehr und nicht weniger, war - wie die konkrete Politik der J.P.-Führung zeigt - Inhalt und Ziel jener lautstark proklamierten Politik der Erneuerung des angeblich so verrotteten Regimes. So unterstützten die J.P. auch die Kabinette Poincaré, Tardieu und Laval. Im Parlament z. B votierten sie für den Young-Plan, für die Übereinkunft von Den Haag über die Rheinland-Räumung: ein system-konformes Parlamentsverhalten hinter einem Nebelschleier von verbalradikaler Propaganda! Das ist etwas ganz anderes als die permanente Obstruktionspolitik der Nationalsozialisten im. Reichstag. Der "Elektoralismus“ der NSDAP war wesenhaft destruktiv im Gegensatz zu der republikanisch-parlamentarischen Haltung der J.P. bei Wahlen und im Palais Bourbon. Außerdem: Politi- 
ker, die den J.P. nahestanden, traten in das Kabinett Tardieu ein. Das waren keine taktischen Anpassungsübungen ${ }^{48}$, denn die diesem Kurs widerstrebenden Kräfte in der Führung wurden kurzerhand ausgeschlossen ${ }^{49}$. Von System-Überwindung oder System-Feindlichkeit konnte in der konkreten Politik der J.P. also keine Rede sein. Leitlinie dieser Politik war vielmehr die Integration der konservativen Rechten in die republikanische Synthese und die Bildung einer modernen rechten Sammlungspartei.

Die nationale Rechte in Deutschland hatte eine solche Entwicklung schon seit langem hinter sich gebracht. Von der nationalistischen Sammlungsbewegung der Vaterlandspartei bis zu den Deutschnationalen der Weimarer Zeit und von den Nationalliberalen bis zur DVP hatte sich die Rechte in Deutschland schon lange zu großen, kohärenten und gut organisierten modernen Massenparteien entwikkelt. Das Stadium fraktionierter Honoratioren-Parteien hatten sie schon lange hinter sich gelassen. Diesen Entwicklungsprozeß versuchten in Frankreich aktivistische Teile der konservativen Rechten aus der Kriegsgeneration in den zwanziger Jahren nunmehr nachzuholen. $\mathrm{Daß}$ dies in militanten, vielleicht auch etwas grelleren Formen geschah, ist mit der Phasenverschiebung in die problembeladene, polarisierende Nachkriegszeit zu erklären. Daß diese Modernisierungsversuche der konservativ-nationalistischen Rechten in Frankreich innerhalb des republikanisch-parlamentarischen Systems erfolgten - im Gegensatz zu der Republik-Ablehnung der nationalistischen Rechten in Deutschland - läßt sich daraus erklären, daß das republikanische System sich schon über vier Jahrzehnte hatte konsolidieren können, vor allem aber, daß die Republik die Bewährungsprobe des Krieges siegreich bestanden hatte. Das alles trug zur Versöhnung der konservativen und katholischen Rechten mit dem politischen System entscheidend bei. In Deutschland dagegen waren Demokratie und Republik aus der Niederlage hervorgegangen, sie traf die feindselige Ablehnung der dem untergegangenen Regime innerlich verbundenen national-konservativen Rechten.

Nachdem der republikanische Integrationskurs trotz etlicher Sezessionen im ganzen hatte erfolgreich durchgehalten werden können, beschloß die Führung der J.P. Anfang 1930 den Parti Républicain National et Social (PRNS) zu gründen, der - wie es im „Bulletin de Liaison“ hieß - eine vom Geiste der J.P. getragene „Partei der republikanisch-nationalen Majorität" sein sollte ${ }^{50}$. Das war der Versuch, die nationalkonservativen Kräfte, die sie bislang in ligistischer Form mobilisiert und für Wahlkämpfe aktiviert hatte, nunmehr in partei-organisatorischem Rahmen zusammenzufassen. Die bislang nur locker strukturierte, ja fraktionierte Rechte sollte in moderner Form organisiert werden, um sie so innerhalb des parlamentarischen Systems unmittelbar zur Wirkung zu bringen. Das Vorhaben scheiterte jedoch am Widerstand der etablierten liberal-konservativen Kräfte. Diese hatten

48 Wie Soucy, French Fascism, S. 63 ff. meint.

49 Hierzu und zum folgenden vgl. Philippet, Taittinger, S. 75 ff.; und AN F7-13.232, 13.235, 12.957, 12958 und 12.961. Auf dem Kongreß der J.P./PRNS sprach Taittinger davon, daß „nous avons besoin d'un parti modéré", die auf einer "trêve des partis" aufgebaut werde (13.232, Bericht vom 1.3. 1930). Es ist interessant, daß Soucy nirgends den PRNS erwähnt. Dieser Versuch der J.P., sich auf der parlamentarischen Ebene zu etablieren, paßt auch nicht in Soucys Interpretation der J.P. als einer prinzipiell systemfeindlichen Bewegung. Ähnlich Wirsching, Weltkrieg, S. $283 \mathrm{ff}$.

so Z. T. in Philippet, Taittinger, S. $75 \mathrm{f}$. 
sich der J.P. im Wahlkampf und im Parlament gern als ligistische Hilfstruppen gegen die Cartel-Gruppierung bedient, nun fürchteten sie diese neue Partei als Konkurrenz. Sie wollten keinesfalls in ihr aufgehen und lehnten daher die Idee einer großen rechts-republikanischen Sammlungspartei ab. Trotz beachtlicher Erfolge in Paris war das Wahlergebnis bei den Wahlen von 1932 für den PRNS wie für die republikanisch-konservative Rechte insgesamt enttäuschend. Taittinger ließ die neue Partei daher nach den Wahlen von 1932 wieder einschlafen. Daß er nun nicht die im Rahmen der J.P. mobilisierten Kräfte in einen außerparlamentarischen oder gar umstürzlerischen Kampf gegen das republikanisch-parlamentarische System führte, sondern die ligistische Form zur Unterstützung der rechtskonservativen und rechtsliberalen Kräfte von Fall zu Fall beibehielt, zeigt einmal mehr, daß es sich - trotz aller verbaler Radikalität - um etwas ganz anderes handelte als um ein system-feindliches „faschistisches“ Phänomen.

Das Scheitern des PRNS-Projektes offenbarte die Stärke und Festigkeit der überkommenen Strukturen der liberalen Rechten. Die Mehrheit ihrer Anhänger sah noch keine Notwendigkeit für neue politische Formen. Sie vermochten ihre Interessen im herkömmlichen „Régime des Assemblées“ und mittels ihrer bestehenden Organisationsmodelle durchaus hinreichend zu wahren. Die Organisationsform einer Liga, die sich - so paradox es klingen mag - um eine außerparlamentarische Mobilisierung zur Unterstützung einer parlamentarischen Politik bemühte, schien der Kooperation von konservativer und liberaler Rechten besser zu entsprechen als eine große Partei der vereinigten Rechten. Die liberale Rechte begrüßte allerdings bereitwillig die modernen Mobilisierungsaktivitäten der J.P. im Zeitalter der Massendemokratie. Insofern waren die J.P. und der PRNS erstens Symptome einer begrenzten Modernisierung der französischen Rechten; zweitens verweist ihre Geschichte auf die aus der Perspektive der traditionellen Rechten noch ausreichende Integrationskraft und damit Funktionsfähigkeit des überkommenen Systems, und drittens war sie ein Indiz für den noch nicht völlig abgeschlossenen Amalgamierungs- und Integrationsprozeß der konservativen Rechten in das republikanisch-parlamentarische System.

\section{IV.}

Die Modernisierung der bislang fraktionierten Rechten war indessen nur ein Aspekt der Erscheinungen, die häufig als "faschistisch“ angesehen werden. Ein weiterer wesentlicher Aspekt enthüllt sich dem analysierenden Betrachter, wenn er die soziale Struktur solcher "Bewegungen“ vor dem Hintergrund des sozioökonomischen Strukturwandels unter die Lupe nimmt, der Frankreich im Gefolge des Ersten Weltkrieges geprägt hat. Dieser hat den erwähnten Amalgamierungs- und Integrationsprozeß vielfach beeinflußt. Die durch ihn hervorgerufenen Widersprüche im republikanischen System sind direkt auf die Entwicklung des Rechtsextremismus durchgeschlagen. Das läßt sich an einer Analyse des „Faisceau“ zeigen ${ }^{51}$. Diese Gruppierung, 1925 von Georges Valois begründet,

51 Allgemein zum „Faisceau“ vgl. Allen R. Douglas, Georges Valois and the French Right. A Study in 
suggerierte durch ihre Namensgebung bewußt eine Identität mit dem italienischen Fascismo ${ }^{52}$. Sie gilt daher in der einschlägigen Literatur bis heute als Prototyp des französischen Faschismus. Ohne Rekurs auf einen problematischen $\mathrm{Fa}$ schismusbegriff kann diese Gruppierung jedoch viel eher als Symptom einer spezifischen akuten sozio-ökonomischen Problemlage begriffen werden ${ }^{53}$. Das wird deutlich, wenn man erstens ihre zentralen programmatischen Aussagen analysiert, dabei aber nicht stehen bleibt, sondern - zweitens - diese in Beziehung setzt zur Struktur und Interessenlage ihrer aktiven Anhängerschaft. Auf solche Weise wird - gerade auch im Vergleich zu den J.P. und ähnlichen Gruppierungen - eine Ortsbestimmung dieser „Bewegung“ innerhalb des republikanischen Systems besser möglich als mit dem Faschismus-Paradigma.

In der politischen Programmatik des „Faisceau“ fallen die Tendenz zu entschlossener Modernisierung sowie ein betonter Fortschrittsoptimismus auf. Das sind zwei Momente, die nicht unbedingt in das gängige Bild „faschistischer" Ideologie mit ihren archaisierenden oder nur vordergründig "modernen“ ideologischen Versatzstücken passen. Valois entstammte der Tradition des Anarcho-Syndikalismus und des Proudhonismus. Als führender Wirtschafts- und Gesellschaftstheoretiker der A.F. hatte er in Maurras' Bewegung einen Cercle Proudhon gegründet. Er wollte Arbeiterschaft und autoritäre Staatsidee miteinander versöhnen. Enttäuscht von der sozialen und politischen Sterilität der A.F. wandte er sich von dieser ab und gründete den „Faisceau" 54 . Als Sammelbewegung linker und rechter Kräfte - so hoffte er - könne dieser die überkommenen sozialen, ökonomischen und politischen Strukturen grundlegend verändern. Er entwarf also ein Konzept der radikalen Modernisierung von Staat und Gesellschaft. Im „Programme de Verdun“, das Valois am 15. Juli 1926 veröffentlichte, wird als eines der „Premiers Objectifs“ der neuen Bewegung verkündet: „[...] organiser rationellement la production“; weiter heißt es: „Coordonner toutes les forces françaises par le moyen d'un Etat unitaire pour réaliser la prospérité" 55 . Valois erläuterte diesen Gedanken immer wieder in seinen Aufsätzen und Schriften. Er forderte einen modernen Staat, den nach seiner Sicht die Revolution von 1789 erstmals hatte verwirklichen wollen ${ }^{56}$. Dieser müsse als „État Serviteur" gegenüber den Interessengruppen mit Hilfe von Planwirtschaft, aber ohne die privatwirtschaftlichen Eigen-

the Genesis of Fascism, Ann Arbor/London 1981; Yves Guchet, Georges Valois ou l'illusion fasciste, in: Revue Française de Sciences Politiques 15 (1965), S. 1.111-1.114; sowie ders., Georges Valois, L'Action Française, Le Faisceau, La République Syndicale, Paris 1975; Jules Levey, Georges Valois and the Faisceau, in: French Historical Studies 8 (1973), S. 279-301; Zéev Sternhell, Anatomie d'un mouvement fasciste en France: Le Faisceau de Georges Valois, in: Revue Française de Sciences Politiques 26 (1976), S. 5-40; Jean M. Duval, Le Faisceau de Georges Valois, Paris 1979; Milza, Fascismes, S. $218 \mathrm{ff} ., 291 \mathrm{ff} . ;$ und Soucy, French Fascism, Kap. 4-7.

52 Die Namenswahl von 1925 sagt nichts über den politisch-ideologischen Charakter dieser Gruppe. Es müßte zunächst, ehe man den Faschismus-Vorwurf erhebt, genau analysiert werden, was Valois damals unter "fascismo" bzw. „faisceau" verstanden hat bzw. verstanden wissen wollte.

53 Diese These wird auf der Basis vor allem der Polizeiakten entfaltet in Müller, Protest, S. 483-507.

54 Später, nach dem Scheitern der „Faisceau“-Idee, versuchte er sich noch einige Male in der Gründung von marginalen Gruppen und endete dann wieder als Anarcho-Syndikalist. Er starb in einem deutschen Konzentrationslager.

s5 Veröffentlicht in: Le Nouveau Siècle vom 15. 7. 1926; vgl. auch ebd. vom 26. 12. 1926 und Abdruck bei Machefer, Ligues et Fascisme en France, S. $40 \mathrm{f}$.

56 Le Nouveau Siècle vom 26.1.1926 und 26. 12. 1926 sowie im „Discours du 11 novembre 1925“, vgl. auch Guchet, Georges Valois, S. $171 \mathrm{f}$. 
tumsverhältnisse anzutasten, Gesellschaft und Wirtschaft modernisieren und Frankreich durch optimalen Einsatz von Technik und Wirtschaft zu einer modernen leistungsfähigen industriellen Gesellschaft machen - ein Prinzip, das nach dem Zweiten Weltkrieg in der „planification à la française“ unter veränderten Verhältnissen realisiert worden ist. Technologischer Fortschritt und ökonomische Innovationen würden soziale Gerechtigkeit und wachsenden Wohlstand für alle gewährleisten. Dann könnten die drei zentralen Ideale des „Faisceau“-Programms verwirklicht werden: „Justice“ - „Prospérité" - „Progrès Technique“.

Gewiß gibt es auch bestimmte, gemeinhin als "faschistisch" angesehene Ideen und Topoi im „Faisceau“-Programm. Polarisierendes Denken im Sinne einer Freund-Feind-Dichotomie ist in den zugespitzten Aussagen der Partei-Intellektuellen offensichtlich. Integraler Nationalismus und Diktaturgedanke finden sich bei Valois, auch Ablehnung des "allmächtigen Parlaments“. Aber gerade gegen letzteres wendet man sich, weil man es als bloße Interessenvertretung der Bourgeoisie ansieht, keineswegs jedoch aufgrund einer Negation des Prinzipes der Volkssouveränität. Außerdem gehört der Diktaturgedanke unleugbar zum jakobinischen Traditionserbe ${ }^{57}$. Auch das Ständestaatmodell, das sich bei Valois findet, wurzelt nicht in sozialkonservativem Denken, sondern in syndikalistischen Vorstellungen ${ }^{58}$. Vor allem jedoch passen die zentralen Gedanken des Programms so gar nicht in ein gewöhnlich als „faschistisch“ angesehenes Denkschema: Der Gedanke des Progrès technique etwa oder das Argument, der moderne, auf „Prospérité" - "Justice“ - „Progrès Technique“ abzielende Staat sei doch schon das Ziel der Revolution von 1789 gewesen ${ }^{59}$, oder die Auffassung, die gesellschaftlichen Interessengegensätze seien nicht abzuschaffen, denn sie seien Motor des gesellschaftlichen und ökonomischen Fortschritts - all diese Gedanken offenbaren eindeutig die Andersartigkeit der „Faisceau“-Ideologie gegenüber der Ideenwelt des italienischen Faschismus und des deutschen Nationalsozialismus; mehr noch: sie verweisen auf die Verwurzelung dieses Programms in der Ideenwelt der Aufklärung und der französischen Revolution ${ }^{60}$. Diese französische politische Tradition

57 Eine genaue Analyse des Diktaturbegriffs bei Valois zeigt, daß diesem Begriff eher Vorstellungen zugrundelagen, die von militärisch-organisatorischem Autoritätsdenken und technologischem Effizienzstreben geprägt waren, nicht aber von „faschistischem“ Führerkult. Vgl. AN F7-13.208 (Polizeibericht vom 1.7. 1926: im „Faisceau“ spreche man diesbezüglich von den Generälen Mangin und Weygand).

58 Gerade dieses Beispiel mahnt zur Vorsicht bei der Zuschreibung bestimmter ideologischer Topoi zur „faschistischen Ideenwelt." Die politische Ideengeschichte ist komplexer, als daß man sich solch simple Zuordnungen erlauben dürfte.

59 Die Ausrichtung auf derartige Ziele zeigt den Unterschied zu jenem neuerdings wieder hervorgehobenen "Modernismus" Hitlers, welcher destruktiven und expansiv-imperialistischen Zielsetzungen diente; vgl. Rainer Zitelmann, Hitler-Selbstverständnis eines Revolutionärs, Stuttgart 1987; vgl. auch Michael Prinz/Rainer Zitelmann (Hrsg.), Nationalsozialismus und Modernisierung. Mit einem aktuellen Nachwort zur Neuauflage, Darmstadt 21994; Hans Mommsen, Noch einmal: Nationalsozialismus und Modernisierung, in: Geschichte und Gesellschaft 21 (1995), S. 391-402; Axel Schildt, NS-Regime, Modernisierung und Moderne. Anmerkungen zur Hochkonjunktur einer andauernden Diskussion, in: Dan Diner/Frank Stern (Hrsg.), Nationalsozialismus in heutiger Perspektive, Gerlingen 1994, S. 3-22.

60 Es ist in diesem Zusammenhang interessant, daß Valois unter der deutschen Besatzung keinerlei Neigung zu irgendwelcher Art von Kollaboration gezeigt hat; vgl. Guchet, Georges Valois, S. $239 \mathrm{ff}$. Vielmehr schrieb er am im Oktober 1939 in Le Nouveau Siècle „[...] désormais, les victoires hitlériennes seront les victoires de Staline“ (zit. bei Rémy Handourtzel/Cyril Buffet, La Collaboration...à gauche aussi, Paris 1989, S. 46). 
war ein wichtiges Hindernis und ein Korrektiv für den Rechtsextremismus in Frankreich, ganz im Gegensatz zu Deutschland, wo die Ideenwelt der französischen Revolution nie wirkmächtig rezipiert, von dominanten Strömungen eher abgelehnt worden war.

Zusammenfassend kann man zur Programmatik sagen: die zentralen Prinzipien wie der Fortschrittsoptimismus, der planerische Impuls, das technokratische Element sowie die zentrale Stellung der Modernisierungsideologie lassen den „Faisceau" keineswegs als ein "stärker dem Idealtypus der totalitären Bewegung "61 sich annäherndes Phänomen erscheinen, vielmehr legen sie den Schluß nahe, im „Faisceau" eine modernistische Protest- und Alternativbewegung zu sehen, die auf Veränderung des Systems des „Régime des Assemblées“ abzielte, ohne jedoch das verbindende Band zu den republikanisch-jakobinischen Grundlagen zu durchtrennen.

Allerdings reicht eine Ideologie- und Programm-Analyse zur historischen Einordnung des „Faisceau“ nicht aus. Ergänzend muß eine Analyse der sozialen Basis und der darin faßbaren sozio-ökonomischen Interessenlage der Anbängerschaft hinzutreten ${ }^{62}$. Die Quellen liefern hier ein aufschlußreiches Bild, und zwar gerade wenn man die den "Faisceau" betreffenden Befunde mit anderen extremistischen Gruppierungen vergleicht.

Die soziale Zusammensetzung der A.F. bietet - wie Eugen Weber es ausgedrückt hat ${ }^{63}$ - ein "nahezu perfektes Portrait einer vorindustriellen Gesellschaft“. Die aktiven Anhänger der J.P. stellen auch nicht gerade das Bild einer modernen Industriegesellschaft dar. Sie erscheinen auf den ersten Blick eher als das typische Abbild der konservativen Rechten: Militärs und gewerblicher Mittelstand sind nahezu genauso stark vertreten wie bei der A.F. Akademische Honoratioren, also Rechtsanwälte, Ärzte, Professoren, Richter etc., bilden zwar bei den J.P. immer noch die stärkste Gruppe, sind aber mit 25,8 Prozent deutlich geringer vertreten als bei der A.F. (34,4 Prozent). Eine bemerkenswerte Differenz jedoch sticht hervor: Die landwirtschaftlich-bäuerlichen Berufe treten bei den J.P. nur mit einer statistisch kaum mehr zu berücksichtigenden Größe von 0,7 Prozent im Gegensatz zu 12,3 Prozent bei der A.F. auf. Dienstleistungsberufe und Berufe des industriellen Sektors stellen hingegen bei den J.P. mit über 33 Prozent einen doppelt so starken Anteil wie bei der A.F. Die Anhängerschaft der J.P. weist sich also als eine soziale Gruppierung aus, die städtisch gepräg $\mathrm{t}^{64}$ und tendenziell schon industriell

61 Wirsching, Weltkrieg, S. 289. Diese Beurteilung des „Faisceau“ läßt sich nur vertreten, wenn man im jakobinischen Erbe der französischen Revolution zwangsläufig totalitäre Tendenzen angelegt sieht.

62 Ausgewertet wurden hierfür folgende Bestände: AN F7-13.208, 13.209, 13.210, 13.211, 13.212 und 12.950; vgl. auch Sternhell, Anatomie, S. 34 ff., der eine Aufstellung unter anderen Gesichtspunkten mit absoluten Zahlenangaben bietet.

63 Weber, Action Française, S. 266.

64 Die Zahlenangaben über die J.P.-Mitglieder in den Akten der Politischen Polizei zeigen dies. 1929: 25000 Mitglieder in Paris, 76000 in der Provinz. Die bei Philippet, Taittinger, S. 117 und S. 133 angegebenen Effektivstärken, die auf zeitgenössischen J.P.-Angaben beruhen, sind gegenüber den Angaben in den Polizeiakten (AN F7-13.232) weit überhöht. Die Polizei (ebd.) gab für April 1926 folgende Vergleichszahlen: Action Française: 14500; Faisceau: 20000; Jeunesses Patriotes: 65000. $\mathrm{Zu}$ jener Zeit hatten der PCF ca. 60000 , die SFIO etwa 110000 Mitglieder; vgl. Annie Kriegel, Le Parti Communiste français sous la Troisième République. Evolution de ses effectivs, in: Rev. Fr. de Science Pol. 16 (1966), S. 20 und S. 35. 
orientiert ist, aber im Kern immer noch von der Honoratiorengesellschaft eines Frankreichs des juste milieu-Bürgertums bestimmt ist ${ }^{65}$. Auch dies deutet eher auf eine Gruppierung der im Wandel befindlichen klassischen (in großen Teilen nunmehr „ralliierten“) Rechten hin als auf rechtsextremistische Regimefeinde.

Dagegen ergibt die Analyse der sozialen Basis des „Faisceau“ ein grundlegend abweichendes Bild: auffallend ist hier im Vergleich zu den anderen Gruppen der relativ hohe Anteil technisch-industrieller und kaufmännisch-industrieller $\mathrm{Be}$ rufsgruppen, darunter zahlreiche Inhaber mittlerer und höherer Führungspositionen 66: Industrielle mit 13 Prozent, leitende Angestellte, Direktoren etc. mit 4,6 Prozent. Nimmt man dazu die mittleren und unteren Angestellten, die meist aus modernen Wirtschaftssparten stammten (Versicherungen, Banken, Großindustrie), dann waren diese Gruppen, zusammen mit den Arbeitern, mit 44,6 Prozent nur wenig geringer vertreten als die den vor-industriellen Sozialgruppen entstammenden Anhänger. Hinzu kommt, daß gerade die bei der J.P. und der A.F. verhältnismäßig zahlreichen vor-industriellen Berufssparten, wie bäuerliche Berufe und Militärs, im „Faisceau“ mit 8,6 Prozent unterdurchschnittlich vertreten sind. Zwar ist dem „Faisceau“ der erhoffte massive Einbruch in die Arbeiterschaft trotz des Beitritts einiger populärer Ex-Kommunisten und Gewerkschaftsführer nicht gelungen, dennoch fällt im Gegensatz zu A.F. und J.P. das Vorhandensein eines, wenn auch kleinen Arbeiteranteils auf. Vor allem aber sind die aktivsten Elemente des berufsständisch organisierten „Faisceau“ die „Union Corporative“ der Ingenieure und Techniker zu nennen. Sie war auch die zahlenmäßig stärkste Gruppe innerhalb der einzelnen Korporationen ${ }^{67}$ :

1. Ingénieurs

2. Voyageurs et représentants de commerce

3. Mécanique et Electricité (auto, aviation)

4. Transports

5. Assurances

6. Employés de commerce

7. Banques et Bourse

Die Auflistung der Korporationen zeigt ebenfalls ein Überwiegen der Angehörigen der modernen Dienstleistungsberufe. Auch die geographische Verbreitung des „Faisceau" verstärkt den Eindruck einer stark in modernen Erwerbs- und Sozialstrukturen wurzelnden politischen Gruppierung68. Angehörige innovativer Wirtschaftssektoren bildeten also weitgehend die aktive Anhängerschaft des „Faisceau“. Die Annahme drängt sich auf, daß ihr Interesse am „Faisceau“ in erster Linie von der modernistischen Programmatik und der berufsständischen Or-

65 Eine Übersicht über die Zahl der "Centuries“ der J.P. in Paris ergibt ein eindeutiges Übergewicht in den großbürgerlich und akademisch geprägten Arrondissements (6., 7., 8., 9., 16. und 17. Arr.), der Schwerpunkt lag im 16. Arr. (AN F7-13.232 Bericht vom September 1926).

66 Vgl. auch Luc Boltanski, Les cadres, La Haye 1982; und ders., Une Réussite: la mobilisation des cadres, in: Lavau/Grunberg/Meyer (Hrsg.), Univers Politique, S. 156-169.

67 Vgl. die Angaben über die "Faisceau des Corporations“, der berufsständischen Gliederung der Bewegung in: AN F7-13.210, April 1926. Die dort gegebenen absoluten Zahlen (vgl. auch Sternhell, Anatomie, S. 34) sind hier prozentual umgerechnet.

68 Die Schwerpunkte lagen im Pariser Becken, in den Industriegebieten des Nordens und Nordostens sowie in den größeren Städten: Bordeaux, Toulouse, Straßburg, Reims, Nancy, St. Quentin, vgl. AN F7-13.210, April 1926; im Gegensatz zu Soucy, French Fascism, S. 113. 
ganisation bestimmt war. Für diese Avantgarde einer aufkommenden Industriewirtschaft gab es unter den bestehenden politischen Parteien und Gruppen des „Régime des Assemblées“ keine Interessenvertretung innerhalb des republikanischen Systems. Es gab auch keine einflußreichen Interessenverbände, die sich ihrer hätten annehmen können. So bot sich der „Faisceau“ als eine Gruppierung an, die ihre sozio-ökonomischen Interessen besser wahren zu können versprach als die etablierten Parteien, die in erster Linie für ihre traditionelle Klientel sorgten. Sie waren neue, nicht im politischen Systemkontext repräsentierte Sozialschichten auf der Suche nach politischer Repräsentanz ihrer sozio-ökonomischen Interessen ${ }^{69}$. Es ist die Frage zu stellen, ob dieser Befund eine sozialstrukturelle Parallele zu Teilen der Wähler- und Anhängerschaft der NSDAP als einer Prostest-Partei zu ziehen gestattet ${ }^{70}$. Immerhin waren Teile des „neuen Mittelstandes" und gewissse auf technologische und sozialpolitische Strukturmodernisierung ansprechende Gruppen dort ebenfalls in erheblichem Maße vertreten ${ }^{71}$.

Der wirtschaftliche und sozialpolitische Immobilismus und Marasmus jener Jahre gaben den Nährboden ab für die Hinneigung einer beachtlichen Zahl von Vertretern dieser modernen Sozialgruppen zum „Faisceau“. Sie vermißten durchgreifende Maßnahmen zur Sanierung und Modernisierung von Wirtschaft und Gesellschaft. Die Politik des „Retour au Normal“, zur Belle Époque der Vorkriegszeit, schien diesen Schichten gründlich verfehlt. Die Kabinette Herriot, Briand und Painlevé erwiesen sich mit ihrer erfolglosen, Aushilfen über Aushilfen produzierenden Wirtschafts- und Finanzpolitik als unfähig, die Probleme der Kriegsfolgelasten zu bewältigen. Das schien für die aktivsten der protestbereiten Elemente innerhalb jener Schichten der Beweis, daß die vorhandenen Institutionen des bestehenden Systems offenkundig unfähig waren, Vertrauen und $\mathrm{Zu}$ kunftsoptimismus zu vermitteln ${ }^{72}$. Hier lagen also die Ursachen für die zeitweilige politische Radikalisierung jener Gruppen, die zum „Faisceau“ fanden. Die Radikalisierung war erstens Ausdruck eines wirtschaftlichen, sozialen und politischen Protestes; und sie war zweitens symptomatisch für unerfüllte Modernisierungshoffnungen einer nicht im republikanisch-parlamentarischen System repräsentierten "neuen Klasse“.

Im Dezember 1925, also fast gleichzeitig wie der „Faisceau“, begründeten Ernest Mercier und einige andere Vertreter wirtschaftlicher und technischer Führungskräfte mit dem „Redressement Français“ eine technokratische Reformbewe-

69 In diesem Zusammenhang ist die Entwicklung der französischen Erwerbsbevölkerung aufschlußreich: von 1906 bis 1931 stieg der Anteil der Angestellten um 60 Prozent, während die Zahl der in Land- und Forstwirtschaft Beschäftigten in diesem Zeitraum um ca. 15,5 Prozent zurückging (1,4 Millionen). Die Zahl der Beschäftigten im Bank- und Versicherungswesen stieg um mehr als 250 Prozent, der im Öffentlichen Dienst um 42 Prozent, in der Chemieindustrie um 87 Prozent, in der Gummi- und Papierherstellung um 95 Prozent, in der Schwerindustrie um 147 Prozent, im Transportwesen um 65 Prozent; vgl. République Française, Annuaire Statistique, 48 (1932).

70 Vgl. Peter Manstein, Die Mitglieder und Wähler der NSDAP 1919-1933, Frankfurt a. M. 1988; und die unten unter Anm. 119 genannten Arbeiten von Falter, Childers u.a.

71 Zur Affinität von „Kleinbürgertum“ und „Faschismus“ vgl. den vorsichtig differenzierenden Vergleich von Heinz-Gerhard Haupt, La petite bourgeoisie en France et en Allemagne, in: Möller u.a. (Hrsg.), Gefährdete Mitte, S. 35-55.

72 Vgl. die überlegt interpretierende Überblicksanalyse von Henri Dubief und Philippe Bernard, The Decline of the Third Republic 1914-1938, Cambridge 1985, Kap. 9-11. 
gung zur politischen und sozio-ökonomischen Modernisierung Frankreichs ${ }^{73}$, die ebenfalls dem Faschismus-Vorwurf linker Zeitgenossen ausgesetzt war. Das kann als ein weiterer Beweis dafür genommen werden, daß sich allmählich jene Gruppen politisch zu Wort meldeten, welche die Modernisierung von Wirtschaft, Gesellschaft und politischem System anstrebten und sich innerhalb des Systems nicht oder nicht hinreichend repräsentiert fühlten. Der „Redressement“ blieb zwar eine elitäre Technokraten-Vereinigung ohne große Breitenwirkung. Aber auch er war unleugbar ein Indiz dafür, daß damals Tendenzen zur Erneuerung und Modernisierung der überkommenen sozio-ökonomischen Strukturen zusammentrafen mit der Befürchtung neu entstandener Sozialschichten, vom bestehenden System in ihren Interessen nicht hinreichend berücksichtigt zu werden. Angesichts der allgemeinen Malaise und der als unzulänglich empfundenen Regierungspolitik begannen sich Zweifel an der Innovationsfähigkeit des politischen System und der Ruf nach Alternativen bemerkbar zu machen.

Welches Gewicht die „facteurs circonstantielles“ - in diesem Fall die Wirtschafts- und Finanzpolitik der Regierungen - für die Entwicklung des „Faisceau“ besaß, zeigt die Tatsache, daß Valois' Gruppierung sofort an Zulauf verlor, als das Kabinett Poincaré (Juli 1928 - Juli 1929) eine erfolgreiche Finanz- und Wirtschaftspolitik durchzuführen begann. Sobald erste Erfolge sich abzeichneten, trat ein politisch-psychologischer Klimaumschwung ein: das Vertrauen in die Fähigkeit des politischen Systems zu erfolgreicher Problemlösung kehrte zurück. Für den „Faisceau“ bedeutete dies das Ende. 1929 war er praktisch aus dem politischen Leben Frankreichs verschwunden. Die ihn primär tragenden Sozialschichten waren einerseits quantitativ noch zu schwach, andererseits waren sie offenbar trotz aller Forderungen nach tiefgreifenden Reformen keineswegs grundsätzliche Gegner des politisch-sozialen Systems, sondern maßen es an seinen Leistungen. Im übrigen muß strikt unterschieden werden zwischen der Führungsequipe und der Basis des "Faisceau“. Diese beiden Elemente des „Faisceau“ waren in ihrer sozialen Zusammensetzung und politisch-ideologischen Ausrichtung keineswegs identisch. Die politisch-ideologische Heterogenität der Führungsgruppe selbst war die Ursache permanenter Richtungskämpfe zwischen rechtsextremistischen Systemgegnern und syndikalistischen Gesellschaftsreformern ${ }^{74}$. In dieser Führungsgruppe waren im übrigen aktivistische Intellektuelle vertreten, die aus dem linksextremen Radikalismus oder aus Kreisen des politisch-gesellschaftlichen Non-Konformismus des „esprit des années trente ${ }^{\text {"75 }}$ kamen und ultra-radikale,

73 Hierzu Müller, Protest, S. 501-520 (dort eingehende Belege für eine Interpretation entsprechend dem hier vorgestellten Erklärungsansatz). Allgemein zum Redressement vgl. Robert F. Kuisel, Ernest Mercier. French Technocrat, Berkeley 1967; sowie - mit fehlgehender Interpretation - Soucy, French Fascism, Kap. 4-7. Weiteres Material aus AN F7 (13.240, 13.241. 13242 und 13.243) ist in meinem unter Anm. 14 angeführten Aufsatz ausgewertet. Zur Einordnung von Merciers Vorstellungen vgl. Patrick Fridenson, L'Idéologie des grands constructeurs dans l'entre-deux-guerres, in: Mouvement Social No. 81 (1972), S. 51-68.

74 Diese Heterogenität, die in Müller, Protest, S. 492 ff., anhand der Polizeiakten nachgewiesen wird, widerspricht Soucys These (Soucy, French Fascism, S. XIII ff.) vom rechtsextremistischen Ursprung dessen, was er "französischen Faschismus" nennt; vgl. ebd., S. 165.

$75 \mathrm{Zu}$ den „non-conformistes des Années Trente“ vgl. jetzt Hans W. Eckert, Konservative Revolution in Frankreich? Die Nonkonformisten der Jeune Droite und des Ordre Nouveau in der Krise der 30er Jahre, München 2000. 
system-feindliche bzw. system-überwindende Ideen zeitweilig in den „Faisceau“ hineingebracht haben. Aber sie dürfen nicht mit dem „Faisceau“ insgesamt identifiziert werden ${ }^{76}$. Auf der anderen Seite ist es aufschlußreich, daß die J.P. und andere Gruppierungen der konservativen Rechten die Avancen des „Faisceau“ zu einer Kooperation gerade wegen dieser Tendenzen der Systemüberwindung ablehnten, aktivistisch-radikale J.P. - und A.F.-Mitglieder aber in kleiner Zahl zu Valois überliefen ${ }^{77}$. Das belegt einerseits die weitgehende Systemintegration der konservativen Rechten wie anderseits das systemüberwindende Image, das der "Faisceau" offensichtlich bei radikaleren Anhängern von J.P. und A.F. besaß. Zusammenfassend kann daher gesagt werden: Soziales Substrat wie geographische Verbreitung ${ }^{78}$ und programmatische Aussagen legen es nahe, den „Faisceau“ primär als Ausdruck des Protestes der aktivistischsten Vertreter jener innovationsorientierter Sozialschichten anzusehen, die modernen Wirtschafts- und Erwerbssektoren angehörten und sich im bestehenden Herrschaftssystem nicht hinreichend repräsentiert sahen.

\section{V.}

Die kurzfristig ebenso erfolgreiche wie aktive Bewegung der „Solidarité Française" (S.F.) bildet in historischer Perspektive den Übergang von der ersten extremistischen Welle der zwanziger Jahre zu den neuen rechtsradikalen Phänomenen der dreißiger Jahre. Diese relativ kurzlebige Gruppierung - sie existierte von 1933 bis 1936 - wird oft nur als marginale Erscheinung bezeichnet; sie sei ein Geschöpf der politischen Ambitionen des Parfum- und Zeitungsmagnaten François Coty gewesen. Ihre Anhänger habe sie im Lumpenproletariat und im NordafrikanerMilieu von Paris und Umgebung gefunden; die Armseligkeit ihrer Doktrin sei nur durch Gewaltsamkeit und Kraftmeierei überdeckt worden. Daß zeitweilig brillante und bekannte Intellektuelle wie Thierry Maulnier und Jean-Pierre Maxence zu ihr stießen, hat die Bedeutung der Gruppe nicht erhöht, aber doch Aufmerksamkeit erregt.

In der Einschätzung der S.F. ist sich die Fachwelt nicht einig. Einige (Machefer, Rémond, Plumyène/Lasierra) meinen, sie habe den Faschismus nur imitiert, sei

76 Es ist bezeichnend, daß der „Faisceau“ - im Gegensatz zu Teilen der J.P. und dem „Croix de Feu“ offenbar keinerlei Bewaffnungstendenzen zeigte, nicht einmal zur Selbstverteidigung (AN F713.210). Daher sind die (pseudo-)militärischen Formen dieser ursprünglich aus einer Frontkämpferorganisation hervorgegangen Gruppierung viel eher der "militärischen Folklore“, der Formveränderung der Politik nach dem Weltkrieg, zuzuschreiben, statt sie als Indiz für eine auf Terror und Umsturz ausgerichtete Parteitruppe nach dem Muster der SA anzusehen. Die von Wirsching, Weltkrieg, S. 290, angeführten "stark atavistischen Züge der Faisceau-Ideologie" sind m. E. eher als Frontkämpfer-Irrationalismen („Schützengraben-Sozialismus“, "Nation des Combattants“) eines spezifischen Zeitgeistes nach dem "Großen Krieg“ ${ }^{2}$ u interpretieren. Atavismen wie „Blutund-Boden-Kult" oder Germanen- bzw. Kelten-Kult findet man dort nicht.

7 Vgl. Wirsching, Weltkrieg, S. 298. Gerade die Tatsache, daß eine ganze Reihe von Persönlichkeiten mit radikalen politischen Ansichten durch nahezu alle diese neuartigen bzw. neu entstandenen politischen Gruppierungen hindurchgingen, aber mit ihren exzentrischen Ideen nirgendwo Fuß fassen konnten, könnte bereits als ein Indiz für die (mindestens relative) Herrschaftssystem-Nähe dieser Gruppierungen dienen.

78 Vgl. die Angaben unter Anm. 68. 
eine sektenartige Liga mit bloß „faschistischen“ Äußerlichkeiten gewesen (Uniformen, Rituale, Führerkult). Andere (Milza) jedoch meinen, mit Cotys Prätorianerkohorten treffe man direkt auf ein Phänomen des französischen „Faschismus"79. Derartige Einschätzungen sagen indessen mehr über die inhaltliche und begriffliche Problematik der Faschismusforschung als über die Bedeutung des Phänomens selbst aus. Aus den verfügbaren Archivmaterialien ist jedoch zu entnehmen, daß gerade diese Gruppe in mehrfacher Hinsicht aufschlußreich für die Eigenart und Entwicklung des französischen Rechtsextremismus ist. Sie kann nämlich als aufschlußreiches Symptom für die unter den Folgen der Weltwirtschaftskrise offenkundig gewordenen Defizite des Systems der republikanischen Synthese und die Veränderungen seiner sozio-ökonomischen Basis angesehen werden.

Um die historische Bedeutung der S.F. zu erfassen, analysieren wir erstens die politische Zielsetzung ihrer Führung und zweitens die Struktur ihrer Anhängerschaft ${ }^{80}$. Innerhalb der Führung der S.F. lassen sich drei Gruppen unterscheiden: Die erste kann unter unserer Fragestellung vernachlässigt werden, obwohl gerade sie zur Klassifizierung der S.F. als „faschistisch“ immer herangezogen wird, da sie den Zeitgenossen durch ihr lärmendes und gewalttätiges Auftreten sofort auffiel. Es ist die Gruppe politischer Abenteurer und ehemaliger Soldaten, wie z.B. des einstigen Offiziers der Kolonialtruppen Jean Renaud, der als ebenso ehrgeiziger wie intellektuell begrenzter Generalsekretär der S.F. agierte ${ }^{81}$. Die Funktion dieser Gruppe war lediglich die Mobilisierung und Organisation der Anhängerschaft; sie war für das para- bzw. pseudo-militärische Gehabe verantwortlich, prägte aber nicht die politischen Inhalte und Zielsetzungen. Zweitens gab es die Gruppe der politisch engagierten Intellektuellen wie Jean Pierre Maxence und Thierry Maulnier ${ }^{82}$, die durch ihre publizistischen Aktivitäten das agitatorische Außenprofil der S.F. zeitweilig mitbestimmten. Sie fanden in Cotys Massenblatt Ami du Peuple eine wirkungsvolle Tribüne für ihre Ideen. Sie sind aber keineswegs typisch für die S.F., zu der sie auch erst ab Frühjahr 1934 stießen, sondern gehörten zu jenen aktivistischen Intellektuellen, die auf der Suche nach einer sozialen Basis für ihre (bisweilen durchaus dem italienischen Faschismus oder dem deutschen Nationalsozialismus ähnelnden) Ideen von einer politischen Gruppe zur anderen wander-

79 Milza, Fascismes, S. 291; und ders., Fascisme Français, S. 145-147; Plumyène/Lasierra, S. 55 ff.; Machefer, Ligues et Fascisme en France, S. 14 f.; Rémond, Les Droites, S. 207. Wirsching ist diesbezüglich nicht ganz eindeutig: Einerseits zählt er die S.F. zu den "faschistischen“ Verbänden (S. 483 und S. 577), andererseits aber nennt er sie einen der „besonders radikalen französischen Rechtsverbände" (S. 600).

80 Die folgenden Ausführungen basieren außer den Angaben in der vorstehend aufgeführten Literatur vor allem auf der unveröffentlichten Dissertation von Alfred Kupferman, François Coty Journaliste et Homme Politique, Thèse de Doctorat de IIIe Cycle, Paris/Sorbonne 1965; sowie auf den Beständen in AN-Serie F7-13.238, 13239 und im Archiv der Polizei-Präfektur PP-346. Ausführlicher als hier habe ich die S.F. analysiert in der Studie: Ambition, argent et protestation. Remarques sur un phénomène d'extrémisme dans la France de l'entre-deux-guerres 1934-1939, in: Gilbert Merlio (Hrsg.), Ni gauche, ni droite: les chassés-croisés idéologiques des intellectuels français et allemands dans l'entre-deux-guerres, Talence 1995, S. 229-244.

81 Wirsching, Weltkrieg, S. 483 bezeichnet ihn irrtümlicherweise als den Begründer.

$82 \mathrm{Zu}$ Jean-Pierre Maxence und Thierry Maulnier, der 1964 in die Académie Française aufgenommen wurde, vgl. Coston, Dictionnaire, Bd. I, S. 684 bzw. S. 678; sowie Sternhell, Anatomie, passim, insbesondere Kap. 7; und die Selbstaussage Jean-Pierre Maxence in: ders., Histoire de Dix Ans 19271937, Paris 1937. 
ten. Typisch für diese Haltung war etwa Maxences Odyssee von der S.F. zum Parti Populaire Français (PPF) und dann zu Pétains Révolution Nationale. Eine Analyse der Gedankenwelt dieser „Non-conformistes“ enthüllt wohl den berühmten "esprit des années trente“, keineswegs aber das politische Profil jener Gruppierung, bei der sie sich jeweils gerade engagierten ${ }^{83}$.

Wichtig in unserem Zusammenhang ist primär der Parfum-Fabrikant und Presse-Zar François Coty und sein Kreis ${ }^{84}$. Von Coty ging Anfang 1933 die Gründung der S.F. aus. Nach seinem Tod im Sommer 1934 sollte sie alsbald wieder in die politische Bedeutungslosigkeit absinken. Coty begründete die S.F., um sich eine Massenbasis für die Durchsetzung seiner politischen Ambitionen zu verschaffen, wozu er schon mehrfach entsprechende Versuche unternommen hatte. 1921 hatte er sich um einen Senatssitz beworben, war aber gescheitert. Später versuchte er, durch massive finanzielle Förderung zahlreicher politischer Gruppen, wie u.a. der A.F., des „Faisceau“, der „Croix de Feu“ und einiger Veteranenverbände, eine Massenbasis für seine politischen Ideen zu finden. So soll er auch den Obersten de La Rocque an die Spitze der „Croix de Feu“ gebracht haben ${ }^{85} .1928$ wollte er mit großem publizistischem Aufwand eine Art internationalen antibolschewistischen Kreuzzug - „La Croisade des Patries“ - initiieren. Ein Erfolg hatte sich nie eingestellt. 1929 bemühte er sich erneut vergeblich, mit einem „Manifeste des Contribuables" eine Massenbasis für seine politischen Ideen zu schaffen. 1932 versuchte er - ebenfalls ohne Erfolg - ihm genehme Kandidaten mit finanzieller und publizistischer Unterstützung zum Wahlerfolg zu verhelfen ${ }^{86}$. Sein Biograph Alfred Kupferman schreibt daher, Coty habe jedes Jahr eine neue Organisation, meist auf den Trümmern der vorhergehenden, zu gründen versucht ${ }^{87}$. Lediglich einige bekannte Autoren wie Georges Bernanos ${ }^{88}$ und Intellektuelle wie die schon genannten Maulnier und Maxence vermochte er für seine Blätter zu gewinnen, ohne daß sie jedoch seine Ideen vollständig teilten. Coty war ein Mann mit offensichtlich nicht zu zügelnden politischen Ambitionen, die er auf jede nur erdenkliche Weise unter Einsatz seines beträchtlichen Reichtums und seiner publizistischen Machtmittel zu verwirklichen suchte. Seit Ende der 20er Jahre hatte er ein großes Presse-Imperium mit über 53 Zeitungen aufgebaut, dessen Kernstücke der schon 1922 von ihm erworbene Figaro und das populäre Massenblatt L'Ami du

83 Wirsching, S. 512, Anm. 463, subsumiert sie gemäß seinem Einteilungskategorien im Gegensatz zu Sternhell und Paul Sérant (ders., Le Romantisme fasciste, Paris 1959) nicht unter den „Faschismus"-Begriff, da sie als elitäre Intellektuellengruppe keine paramilitärische Organisation, keine Parteiorganisation etc. intendierten und - was für etliche wie Maxence, Maulnier, Drieu La Rochelle kaum zutrifft - „zur politischen Praxis ein distanziertes Verhältnis behielt[en]“.

84 In Ajaccio unter dem Namen Spoturno 1874 geboren, gestorben in Paris 1934; er war 1931 auch zum Bürgermeister seiner Heimatstadt gewählt worden.

85 Dazu Kupferman, Coty, S. 167. Vgl. auch Jacques Nobécourt, Le colonel de La Rocque, 18851946 ou les pièges du nationalisme chrétien, Paris 1996, Kap. 6.

86 Er unterstützte die Kandidaten des Front National mit seiner Presse; rein „Cotyistische“ Kandidaten - Männer aus seinem persönlichen politischen Umfeld, wie etwa Jacques Ditte und Henri Lauridan - konnten jedoch nur etwa 8 Prozent der Stimmen auf sich ziehen; vgl. Kupferman, Coty, S. 173.

87 Vgl. Kupferman, Coty, S. 167; eine Aufstellung der von Coty geförderten bzw. begründeten politischen Gruppen ebd., S. 245 ff.

88 Dieser schrieb seit 1932 regelmäßig im Figaro und engagierte sich zeitweilig massiv für Coty; vgl. Kupferman, Coty, S. $168 \mathrm{ff}$. 
Peuple waren ${ }^{89}$. Den Figaro machte er ab 1927 zu einem eindeutigen Kampfblatt was zu schweren finanziellen Verlusten führte. Mit dem Ami du Peuple, dem „journal à deux sous“, gründete er 1928 eine ebenso populäre wie demagogische Boulevardzeitung, die rasch ein Verkaufserfolg wurde: ihre Auflage steigerte sich von $700000 \mathrm{im}$ Jahr 1928 auf 1 Million im Jahr 1930. Sie sollte seinen politischen Ideen Eingang bei den „kleinen Leuten“ verschaffen, mit deren Hilfe er seine Ambitionen zu verwirklichen hoffte.

Anfang 1933 schien ihm die innenpolitische Lage eine günstige Konstellation für die Gründung einer eigenen politischen Gruppierung zu bieten, um an die Durchsetzung seiner politischen Zielvorstellungen zu gehen: Die rigorose Deflationspolitik der Regierung (Plan Cheron) hatte heftige Protestaktionen von Veteranenvereinigungen, von Interessenverbänden der Bauern, des Einzelhandels, des gewerblichen Mittelstandes und der Steuerzahler hervorgerufen. Rentner, Pensionäre, kleine Sparer und Sozialversicherungsempfänger spürten - wie die Präfekturberichte zeigen 90 - unmittelbar und immer härter die Auswirkungen dieser Politik. Coty sah in ihnen ein großes Reservoir potentieller Anhänger ${ }^{91}$. Sie würden fraglos empfänglich sein für eine seiner zentralen politischen Ideen, den populistischen Anti-Kapitalismus, bei dem er zwischen einem negativen, "plündernden" Kapitalismus der internationalen Finanzwelt und einem guten, dem „produktiven" Kapitalismus der nationalen Arbeit unterschied. Mit solchen Parolen, zu denen ein militanter Antikommunismus kam, hoffte er, die Massen für das eigentlich zentrale Element seiner politischen Ideenwelt gewinnen zu können: die Staatsreform ${ }^{92}$.

Mit dieser Idee stand er damals nicht allein. Im Gegenteil, er stand in einer seit längerem immer breiter werdenden zeitgenössischen Problemdebatte. Seit Ende des Krieges war die Diskussion über die Unzulänglichkeiten des bestehenden parlamentarischen Systems, des „Régime des Assemblées“, und die Möglichkeiten seiner Reform zunehmend intensiver geworden. Zunächst standen die Frontkämpferverbände der Anciens Combattants an der Spitze dieser Reformdiskussion; sie waren indes in ihrer überwiegenden Mehrheit - wie Antoine Prost nachgewiesen hat ${ }^{93}$ - alles andere als antirepublikanisch oder gar „faschistisch“. Seit Ende der 1920er Jahre, vollends als Anfang der 1930er Jahre die Unfähigkeit von Parlament und Regierung sich erwiesen hatte, mit den sozialen und ökonomischen Problemen fertig zu werden, nahm die Debatte um die Staatsreform an Breite und Dynamik zu. In nahezu allen „familles politiques“ Frankreichs fand sie

89 Vgl. hierzu Kupferman, Coty, Kap. V und VI.

90 Insbesondere AN F7-13.042 (Monatsberichte 1931-1936) sowie 12.962 (Berichte 1930-33).

91 Coty legte im Frühjahr 1933 unter großem publizistischen Aufsehen ein ausführliches „Programm der Staatsreform" vor, das er in der Presse und durch Maueranschläge in vielen Städten bekannt machte. Im November 1933 ließ er es dann als Broschüre in einer Auflage von über 200000 Exemplaren drucken und auf etlichen Großveranstaltungen (zwischen Oktober und Dezember 1933) agitatorisch auswerten.

92 Zur Entwicklung der Staatsreform-Diskussion vgl. Jean Gicquel und Lucienne Sfez, Le Problème de la Réforme de l'Etat en France depuis 1934, Paris 1965; sowie Antoine Prost, Les Anciens Combattants et la Société Française 1914-1939, Paris 1977, Bd. 3, Kap. 6: „La Réforme de l'Etat“; sowie Kupferman, Bd. II, S. 207-217; und Marc Simard, Doumergue et la réforme de l'État en 1934. Le dernière chance de la Troisième République, in: French Historical Studies 16 (1990), S. 576-596.

93 Siehe Anm. 93. 
statt - mit Ausnahme der grundsätzlichen Systemgegner wie der Kommunisten und der rechtsextremistischen Ultras. Im Kern ging es dabei um die Stärkung der Exekutive, die Disziplinierung des Parlamentes und die Relativierung des Parteienmonopols, also um eine Effektivierung des bestehenden Systems, oder zugespitzt formuliert: um politische Modernität; nicht aber um Zerstörung der demokratischen Republik! Ein historisch-politisch allzu verengter, exklusiv auf die parlamentarischen Strukturen der III. Republik ausgerichteter Blick neigt dazu, die damaligen Staatsreformideen als systemzerstörend, als antirepublikanisch, gar als „faschistisch“ zu qualifizieren. Ein Vergleich mit der gaullistischen Verfassung der V. Republik zeigt indessen, daß die Reformprojekte jener Zeit im Kern tatsächlich ähnliche Strukturreformen für Exekutive und Parlament beinhalteten ${ }^{94}$.

Damit entsprachen Coty und sein Kreis also durchaus einer der vorherrschenden Tendenzen jener Jahre. Das ist häufig übersehen worden. Die S.F. kann also nicht von vornherein als „faschistische“ Gruppierung angesprochen werden, mögen auch einige ihrer konkreten Erscheinungsformen - Uniformen und neuartige Polit-Rituale - dies vielleicht den Zeitgenossen suggeriert haben. Cotys Vorstellungen - und die S.F. als deren Vehikel - waren Teil der breitgefächerten Staatsreform-Diskussion. Ihr populistischer Antikapitalismus traf zudem auf die Stimmungslage bestimmter protestlerischer Sozialgruppen. Die Ereignisse um den 6. Februar 1934 gaben der S.F. zunächst noch einigen Auftrieb, aber der finanzielle Niedergang Cotys und sein baldiger Tod (Juli 1934) nahm ihr dann die materielle und politisch-organisatorische Basis ${ }^{95}$.

Als Teil der in nahezu allen politischen Parteien und Gruppen geführten Staatsreform-Debatte war die S.F. auch Ausdruck eines Modernisierungs-Defizites des politischen Systems der Dritten Republik; sie war zudem mit der relativen Breitenwirkung ihres antikapitalistischen Populismus Ausdruck ökonomischen und sozialen Protestes bestimmter Sozialgruppen. In beiden Momenten verweist sie auf ein Partizipationsdefizit der "société bloquée“. Eine Analyse der aktivistischen Anbängerschaft - erstellt aufgrund der verfügbaren Polizeiakten - bestätigt diesen Befund und erweitert ihn zugleich: Das traditionelle Frankreich der vor-industriellen Sozialgruppen ist mit insgesamt 43 Prozent im Vergleich zu den anderen untersuchten Gruppierungen in der S.F. am wenigsten vertreten. Jedoch tritt innerhalb dieser Kategorie der bäuerliche Mittelstand mit 22 Prozent auffallend hervor; er ist hier fast doppelt so hoch wie bei der doch im bäuerlichen Frankreich durchaus verwurzelten A.F., wohingegen der gewerbliche Mittelstand am geringsten von allen hier betrachteten Gruppen vertreten ist. Die Zahlen spiegeln den bäuerliche Zorn über die rapide Verschlechterung der landwirtschaftlichen Lage und über die Unfähigkeit der Regierung, dieses Problem zu bewältigen. Ab 1930 war es zu einem rasanten Preisverfall der Agrarprodukte gekommen, nicht zuletzt hervorgerufen durch den mit der beginnenden Arbeitslosigkeit einsetzenden

94 Die damalige "political correctness" stigmatisierte Vorstellungen als häretisch, vulgo "faschistisch“, die später unter Daladier und mehr noch unter de Gaulle akzeptiert wurden.

95 Hierzu ausführlich Müller, Ambition, S. 237 ff. Die S.F. wurde von Nachfolgekämpfen zerrissen. Nun kamen grundsätzliche Regimegegner auch in der Propaganda zu Wort. Damit aber war ihr Ende besiegelt: sie verlor die Masse ihrer Anhänger. 
Rückgang der Nachfrage96. Das hatte zu einer beachtlichen politischen Mobilisierung auf dem Lande geführt. Offensichtlich haben die radikaleren Elemente der Bauern sich der S.F. zugewandt, soweit sie nicht in den damals aufkommenden anderen Ausdrucksformen des organisierten bäuerlichen Massenprotestes wie der „Dorgères“-Bewegung oder dem „Front Agraire“ eine Alternative fanden.

Ein eindeutiges Bild ergibt die Statistik der aktiven Anhängerschaft bei den Sozialgruppen, welche die moderne Industrie- und Dienstleistungsgesellschaft repräsentierten. Ihre Spitzengruppe - Industrielle, Ingenieure, leitende Angestellte ist bei der S.F. überhaupt nicht vertreten. Diese bevorzugte eher den intellektuell anspruchsvolleren „Redressement“, soweit sie sich nicht im „Croix de Feu“ engagierte. Die sozial darunter stehenden Schichten - kleine Angestellte, untere Beamte - sind jedoch mit 13 Prozent recht beachtlich vertreten, allerdings nicht so stark wie beim „Faisceau“ oder bei den J.P. Es waren jene Bevölkerungskreise, die durch Arbeitslosigkeit und Deflationspolitik in hohem Maße betroffen waren. Der öffentliche Dienst z.B. wurde in seinen unteren Rängen vergleichsweise schlecht bezahlt, seine Gehälter waren obendrein zwischen 1919 und 1930 nie angehoben worden.

Ganz auffallend jedoch ist im Vergleich zu den anderen analysierten Gruppierungen folgendes: Mit fast einem Drittel der militanten Anhängerschaft - 32 Prozent - sind die von der Krise und der Deflationspolitik am meisten betroffenen Schichten, die Pensionäre, Rentner, Berufslose (wohl ungelernte Arbeitslose und Jugendliche ${ }^{97}$ ohne abgeschlossene Ausbildung) stark vertreten. Nimmt man Arbeiter sowie untere Beamte bzw. Angestellte hinzu, so machen die Angehörigen der wirtschaftlich schwächeren Schichten 57 Prozent der aktivistischen Anhängerschaft der S.F. aus. Den genannten Gruppen schien die S.F. als politisches Transmissionsorgan ihres Protestes besonders geeignet zu sein, während dem gewerblichen Mittelstand und den Bauern noch andere Möglichkeiten des organisierten radikalen Protestes blieben.

Rechnet man die hier relevanten Gruppen zusammen: bäuerlicher und gewerblicher Mittelstand mit 36 Prozent, Angestellte, kleine Beamte und Arbeiter mit 25 Prozent sowie Rentner, Pensionäre etc. mit 32 Prozent, dann ergibt sich, daß über 90 Prozent - also fast die Gesamtheit der Anhänger - aus den durch Krise und Krisenbekämpfungsmaßnahmen am meisten betroffenen Sozialgruppen kamen. Es waren exakt jene Schichten, die sich zunehmend von den ihre sozio-ökonomischen Interessen bislang vertretenden Parteien nicht mehr hinreichend repräsentiert fühlten. Sie fanden in der S.F. erstmals eine Plattform für ihr Protest-Engagement ${ }^{98}$. Vor allem erhofften sie von den Staatsreformplänen der Coty-Bewegung

96 Zwischen 1929 und 1935 sank der Preis für den Zentner Weizen von 184 auf 74 Francs, der des Hektoliters Wein von 154 auf 64 FF; vgl. Bernard/Dubief, Decline, S. 193. Vgl. auch Pierre Barral, Les Agrariens Français de Méline à Pisani, Paris 1966; sowie Gordon Wright, Rural revolution in France. The Peasantry in the XXth Century, Stanford 1964.

97 Eine Auswertung des Faszikels PP-346 über die S.F. zeigt, daß 78 Prozent der Aktivisten unter 35 und 43,5 Prozent sogar unter 25 Jahren alt waren.

98 Die Polizeiberichte (ebd.) geben für November 1935 eine Anhängerzahl von ca. 60000 für ganz Frankreich an, von denen etwa 20000 Beiträge zahlten. Das ist verglichen mit den ca. 80000 Mitgliedern des PCF 1935 (gemäß Claude Willard, Geschichte der französischen Arbeiterbewegung, Frankfurt a. M./New York 1981, S. 147) eine nicht unerhebliche Zahl. Die Francisten vermochten 
ihr Heil. Und die Führung der S.F. versuchte diesen Erwartungen zu entsprechen $^{99}$. Wenn man nämlich die konkreten politischen Aktivitäten betrachtet, dann haben sie nichts zu tun mit dem lärmenden Antikommunismus der S.F.-Propaganda, viel mehr jedoch mit den sozio-ökonomischen Interessen ihrer Klientel und deren mangelnder Wahrnehmung durch das Parlament. So kooperierte die S.F. mit der Führung des Bundes der Steuerzahler, nahm Kontakte mit Bauernverbänden sowie Kleinhändlern und Gewerbetreibenden auf und gründete einen Sparerschutzbund ${ }^{100}$. Wenn die S.F. einen „neuen Staat" forderte, der von Arbeitern, Bauern und Kleinbürgern getragen werden sollte, dann zielte sie nicht auf einen Umsturz der Republik, auf ein neues Regime, sondern auf eine stärkere Berücksichtigung dieser Sozialschichten innerhalb des Regimes. Maxence schrieb in diesem Sinne: „Les ouvriers et classes moyennes sont les sacrifiées d'un régime frappé de décrépitude, de sénilité et de mort!"101. Unter Berufung auf die Ideen von 1789 forderte man die Emanzipation der Unterschichten von dem gegenwärtigen unfähigen politischen Führungspersonal der Republik, spielte loyalen Republikanismus gegen korrupte und egoistische Deputierte aus ${ }^{102}$. Das war keine „Legalitätstaktik“, wie sie Hitler seit dem Reichswehrprozeß als Strategie zum Sturz der Republik proklamiert hatte; das war vielmehr ein unter Berufung auf die Grundlagen der "republikanischen Moral“ erfolgender Aufruf zur besseren Repräsentation der Nation bzw. zur Verbesserung der Repäsentationsmechanismen der Republik.

Eine strukturelle und funktionale sowie system-orientierte Analyse kann - so darf festgestellt werden - die extremistischen Gruppierungen und „Bewegungen“ in der späten Dritten Republik historisch präzise erfassen und erklären, ohne auf einen letztlich stets problematischen Faschismus-Begriff rekurrieren zu müssen. Ein solcher Zugriff erfaßt die in Frage stehenden Gruppierungen als Symptome einer bestimmten nationalen Problemlage in der Zwischenkriegszeit: Diese Lage war in den zwanziger Jabren bestimmt durch die Kriegsfolgelasten, in den dreißiger Jabren kamen noch die Auswirkungen der Weltwirtschaftskrise hinzu. Schon im Ersten Weltkrieg hatte der bislang relativ langsam vonstatten gehende sozioökonomische Wandel sich beschleunigt. Die politischen Auswirkungen dieser

kaum die Hälfte davon aufzubieten. Aufschlußreich auch der Polizeibericht vom Februar 1935, der einen starken Zulauf Jugendlicher registriert (ebd.).

99 Vgl. die Flugblätter, Aufrufe und Versammlungsberichte in: AN F7-13.238 und 13.239 bzw. PP346; Maxence schrieb z. B. in einer Wahlzeitung im Oktober 1935, die S.F. wolle mit Hilfe der Jugend und der Intelligenz „organiser une société forte, diverse, juste qui dans toutes les circonstances protègera les libertés " (PP-346, Bericht vom 12.10. 1935). Populistischer formulierte es ein S.F.-Präsidiumsmitglied (PP-346, Bericht vom 15. 2. 1935): „C'est un devoir de la Solidarité Française d'assurer du travail aux Français d'abord!" Die S.F. richtete u. a. Sozialstationen und Arbeitsvermittlungsstellen ein.

100 So z. B. Maxence auf dem Korporations-Kongreß vom 30.6. 1935 (AN F7-13.239, Bericht vom 1.7. 1935): „Le peuple des travailleurs arrachera des mains des profiteurs les actions des grandes entreprises!“ Typisch waren auch die im Verlauf einer Veranstaltung zur Abstimmung gebrachten „Ordres du Jour“, z. B. vom 24. 8. 1933: „[...] (les participants) [...] dénoncent devant l'opinion française les méfaits des politiciens, adversaires de l'épargne populaire et de la sécurité nationale" (dito: AN F7-13.238 vom 14. 9. 1933).

101 In: L'Ami du Peuple vom 7. 5. 1935 (in: PP-346).

102 In Nr. 12 des Journal de la Solidarité Française vom 10.11. 1934 (AN F7-13.239) hieß es entsprechend: „Å bas les voleurs, à bas Herriot! A bas les radicaux, à bas cette députaille d'affaires!“”. 
Wandlungsprozesse verstärkten sich unter dem Druck der finanziellen und wirtschaftlichen Probleme. Das politische System, das "Régime des Assemblées“, hatte Schwierigkeiten, flexibel und effektiv auf die komplexe Problemlage zu reagieren. Somit sind die behandelten „Bewegungen“ und Gruppen als Ausdruck bestimmter Repräsentations-Defizite - und damit eben auch Modernisierungsdefizite - des politischen Systems in einer akuten Problemsituation anzusehen. Sie reflektierten diese Defizite allerdings mit gewissen inhaltlichen Akzentunterschieden.

Die J.P. spiegeln das politische Modernisierungsbedürfnis bestimmter rechtskonservativer Kräfte wider, die glaubten, ihre Interessenwahrung nunmehr nur noch durch die Bildung einer "modernen“ rechten Sammlungsbewegung und damit durch ihre stärkere Integration in das republikanisch-parlamentarische System realisieren zu können. Im „Faisceau“ wiederum verbanden sich Modernisierungstendenzen und politisch-sozialer Protest von im Entstehen begriffenen Sozialgruppen der modernen Industrie- und Dienstleistungsgesellschaft. Er kann als Ausdruck der Modernisierungsambitionen dieser Schichten angesehen werden, die sich im System der republikanischen Synthese noch nicht hinreichend vertreten sahen. Sie strebten daher zu modernen, das überkommene System tiefgreifend verändernden Formen politischer Repräsentanz und sozio-ökonomischer Interessenwahrung. Die S.F. dagegen akzentuierte den Protest der von der Krise am meisten Betroffenen, nämlich bestimmter sozial schwächerer Bevölkerungschichten. Diese sammelten sich um einen organisatorischen Kern herum, der im wesentlichen von staatsreformerischen Kräften gebildet wurde. Deren Reformideen schienen ihnen eine Möglichkeit zu bieten, um ihren Protest und ihre sozioökonomischen Aspirationen auszudrücken. Für die politischen Ambitionen des Pressetycoons Coty sollten sie indes die Massenbasis bilden, mit der er seine sich durchaus noch im Rahmen der "republikanischen Moral“ befindlichen Staatsreform-Ideen durchzusetzen hoffte.

Die unterschiedliche Erfolgsbilanz der genannten Gruppen wirft ein bezeichnendes Licht auf wichtige Strukturbedingungen des französischen politischen Systems. Der Mißerfolg des „Faisceau“ belegt, daß die ihn tragenden Sozialschichten qualitativ wie quantitativ innerhalb der französischen Gesellschaft noch zu schwach waren, um sich auf Dauer durchsetzen zu können. Das unterschied sie von der Lage in Deutschland, wo diese Sozialgruppen schon im Kaiserreich ein weitaus größeres Gewicht erlangt hatten, wo sie sich schon seit längerer Zeit effektiv organisiert hatten und gewohnt waren, ihre Interessen überwiegend nicht über Parlament und Parteien in die politische Entscheidungssphäre zu transportieren. Sie hatten daher dem parlamentarischen System gegenüber keine tragfähige Bindung entwickeln können. In Frankreich reichte zwar das Gewicht dieser Sozialgruppen schon aus, um ihre Gravamina zeitweilig in organisierten Protest umzusetzen, nicht aber, um sich dauerhaft innerhalb des politischen Systems zu etablieren oder es außer Balance zu bringen. Die Kurzlebigkeit der S.F. zeigt die Abhängigkeit ephemerer Protestgruppen von bestimmten Konstellationen. Für die J.P. dagegen ist die Bilanz ambivalent. Sie erreichten ihr Maximalziel, die Gründung einer großen rechtsrepublikanischen Integrationspartei, nicht. Der Mehrheit der liberalen Bourgeoisie und der moderaten Rechten genügten zur Wahrung 
ihrer Interessen in den zwanziger Jahren noch immer die vorhandenen Transmissionsmechanismen. Die J.P. indessen verstärkten diese durch ihre zeitweilig erfolgreiche Massenmobilisierung. Eine ähnliche, letztlich systemstabilisierende $\mathrm{Ba}$ lance von Distanz und Einbindung war bei der deutschen Rechten gegenüber der Republik von Weimar nicht gegeben. Vielmehr verharrte die gesamte Rechte in feindseliger Distanz zum Staat, weitgehend bereit, unter gewissen Umständen mit dessen Feinden zusammenzugehen.

\section{VI.}

Frankreichs Entwicklung in den dreißiger Jahren zeigte dann eindrucksvoll die Flexibilität des republikanischen Systems. Es gelang in der sich zuspitzenden Krise, zunächst durch Öffnung nach links und danach durch system-interne Modifikationen auf der Basis einer Mitte-Rechts-Mehrheit, das Herrschaftssystem wenigstens so zu stabilisieren, daß es funktionsfähig - und das heißt auch: integrationsfähig - blieb.

Zunächst hatte es den Anschein, als ob das „Régime des Assemblées“ nicht in der Lage wäre, den doppelten Problemdruck von Weltwirtschaftskrise und noch immer nicht abgetragenen Kriegsfolgelasten zu bewältigen. Der Handlungsspielraum der Exekutive wurde immer enger. Die rasche Folge von Kabinetten zeigt dies: Sieben Kabinette in zwei Jahren (von Dezember 1932 bis Dezember 1934). Keine dieser Regierungen war fähig, die unter dem Krisendruck immer stärker divergierenden Interessengegensätze zu bündeln. Allzu schmale, daher zerbrechliche parlamentarische Mehrheiten vermochten nicht, die notwendigen unpopulären Maßnahmen durchzuführen. Ihre wirtschaftsliberale Orthodoxie versperrte den Ausweg staatlicher Interventionen. Eine verfehlte Deflationspolitik verschärfte die Krise. Ergebnis waren wachsender Unwillen und Empörung; Streiks, Demonstrationen und innere Unruhen. Das bestehende System schien unfähig, den Interessen breiter Bevölkerungsgruppen zu entsprechen. Politskandale ruinierten obendrein das Prestige der Regierenden. Nach dem blutigen Aufruhr vom 6. Februar 1934 schien sich mit dem Kabinett Doumergue zunächst die Möglichkeit einer breiten konservativ-liberalen Zusammenfassung abzuzeichnen, ein Kabinett der „Union Nationale“, gleichsam die etwas konventionellere Form dessen, was den J.P. Taittingers vorgeschwebt hatte. Doumergue wollte sich mit einer Verfassungsreform, welche die Stärkung der Exekutive vorsah, ein Instrument zur Bewältigung der Krise verschaffen. Dieser Lösungsversuch der Krise scheiterte schon nach wenigen Monaten. Nunmehr trat mit der Bildung eines VolksfrontArrangements das ein, was Mitte der zwanziger Jahre von der Rechten befürchtet wurde: die Wendung der Radicaux nach links durch die Einbeziehung der bislang nicht in den Systemmechanismus integrierten sozialistischen und (in Grenzen) auch der kommunistischen Linken. Das rief eine starke Polarisierung in der politischen Szenerie hervor. Es kam zu einer „rapiden Beschleunigung der Desintegrationstendenzen“. Damals schien „[...] der Grundkonsens, [...] der die Republik bislang [...] zusammengehalten hatte, zu zerrinnen“; das Land verlor „zunehmend an Lösungskapazitäten im Inneren wie an Handlungsfähigkeit auf der inter- 
nationalen Szene"103. Eine eingehende Analyse, die wir hier nur skizzenhaft nachvollziehen können, vermag jedoch zu zeigen, daß die Integrationskraft der republikanischen Synthese erheblich stärker gewesen ist, als die Zeitgenossen meinten und sogar noch manche rückschauende Analytiker glauben ${ }^{104}$. Die Entwicklung bedeutete keine innere Zerfallserscheinung, sondern sie war eher Ausdruck des von Michel Winock so eindrucksvoll beschriebenen „Fièvre hexagonale“105, einer jener die Nation aufwühlenden Entwicklungsschübe der Republik, die Veränderungen innerhalb des politischen Systems einleiten. Eine Analogie zur deutschen Situation zwischen 1929 und 1933 liegt daher keineswegs vor.

Der „fiebrige“ Entwicklungsschub der dreißiger Jahre trat in zwei Erscheinungsformen auf: einmal in einem neuen Extremismus, den Soucy die „zweite Welle des französischen Faschismus" genannt hat ${ }^{106}$, und der auf Veränderung des Herrschaftssystems abzielte, dann aber schließlich integriert oder marginalisiert wurde. Das zweite Phänomen war die Volksfront-Bewegung, die mit der Bildung der Volksfront-Regierung 1936 eine Öffnung des republikanischen Systems nach links brachte. So unterschiedlich diese beiden Erscheinungen auch waren, eines war ihnen gemeinsam: Volksfront wie neuer Extremismus waren Ausdruck des Bemühens, eine neue, allerdings jeweils völlig verschiedenartige gesellschaftliche und politische Integration zu erreichen.

Im Rabmen des neuen Extremismus entstanden militante Organisationen, von denen zwei - nämlich der PPF des Ex-Kommunisten Jacques Doriot ${ }^{107}$ und die ursprünglich als Kriegsteilnehmerorganisation begründete "Croix de Feu“ des Colonel de La Rocque - zu Massenbewegungen wurden. Der PPF des Jacques Doriot ist in unserem Zusammenhang nur wegen seiner Herkunft aus dem linken Extremismus interessant. Diese Partei ist in nur drei Jahren zu einer Massenpartei hochgeschossen ${ }^{108}$, dann aber bis Kriegsausbruch wieder rasch geschrumpft und schließlich marginalisiert worden ${ }^{109}$. Erst im Krieg kam diese Partei als ein national-revolutionäres Phänomen des radikalen Kollaborationismus wieder zu einer gewissen Bedeutung. Sie entstand aus einer ursprünglich „anti-faschistisch“ motivierten national-kommunistischen Anti-Komintern-Dissidenz. Doriot, damals noch Mitglied des Zentralkomitees des PCF und Chef des mitgliederstarken Be-

${ }^{103}$ So Wilfried Loth, Geschichte Frankreichs im 20. Jahrhundert, Frankfurt a. M. 1992, S. 47.

104 Vgl. hierzu die ein strenges Modernisierungskriterium zugrundelegende Analyse von Loth und die erheblich abgewogenere Conclusion von Berstein, La France des Années Trente, S. 170f., der die Krise in einen größeren historischen Zusammenhang einordnet.

105 Michel Winock, La fièvre hexagonale. Les grandes crises politiques 1871-1968, Paris 1986.

106 Vgl. Robert J. Soucy, French Fascism. The second wave, 1933-1939, New Haven/Conn./London 1995.

107 Über die fraglos charismatische Persönlichkeit Doriots und den PPF vgl. die große Biographie von Jean-Paul Brunet, Doriot. Du Communisme au Fascisme, Paris 1986; dazu meine Bemerkungen in: Francia 17/3 (1990), S. 170-191.

108 Zwischen 1934 und 1937 stieg die Anhängerschaft bzw. die Zahl der Sympathisanten von 30000 auf etwa 100000 an. Nach Brunet überstieg jedoch die Zahl der Aktivisten des PPF nie 15000, vgl. Jean-Paul Brunet, Doriot. Du Communisme au fascisme, in: L'Histoire 21 (März 1979), S. 22-29; und Brunet, Doriot, S. $229 \mathrm{f}$.

109 Vgl. dazu auch die zutreffende Beurteilung bei Wirsching, Weltkrieg, S. 484 f. Plumyène/Lasierra, Les Fascismes Français, S. 110, halten den PPF für die einzige authentische französische faschistische Partei; Dieter Wolf, Die Doriotbewegung. Ein Beitrag zur Geschichte des französischen Faschismus, Stuttgart 1967, sieht im PPF der Vorkriegszeit eher Ausdruck eines virulenten Antikommunismus. Für Brunet gibt es eine kommunistische und eine faschistische Phase bei Doriot. 
zirkes von St. Denis, schlug bereits vor der strategischen Wende der Komintern eine antifaschistische Volksfront-Strategie vor, konnte sich aber weder in Moskau noch in der nationalen Leitung des PCF durchsetzen, sondern wurde ausgeschlossen. Im Rahmen der Anti-Volksfront-Mobilisierung des Bürgertums vermochte er zunächst zahlreiche Anhänger aus nicht-kommunistischen Kreisen zu gewinnen. Eine große Anti-Volksfront-Sammlungsbewegung zu begründen gelang ihm nicht. Ab 1938 war der Niedergang des PPF offenkundig.

Auf der sozialistischen Linken gab es analoge Erscheinungen: Der Philosophieprofessor Marcel Déat war seit Ende der zwanziger Jahre einer der Hoffnungsträger der SFIO ${ }^{110}$. Er galt als der Dauphin Léon Blums. Überzeugt, daß die klassischen Lehren des Sozialismus keine Problemlösungen für die gegenwärtigen Krise boten, interessierte er sich zunächst für so unterschiedliche politisch-gesellschaftliche Konzeptionen wie die Franklin D. Roosevelts, van Zeelands und Hitlers. Sodann entwickelte er unkonventionelle Ideen: einen reformistischen Sozialismus, gestützt auf die Mittelschichten im nationalen Rahmen. Darin sah er die Voraussetzung für eine erfolgreiche Bekämpfung des „Faschismus“. Mit solchen Gedanken konnte er sich innerhalb der Partei nicht durchsetzen. Es kam zum Bruch. Mit der Gruppierung der „Néosocialistes“ scheiterte er nach kurzem Aufschwung. Nach der Niederlage von 1940 engagierte er sich als extremer Kollaborateur für eine nationale Einheitspartei und für ein bedingungsloses Zusammengehen mit Hitler-Deutschland ${ }^{111}$. Bei aller Unterschiedlichkeit der Persönlichkeiten und der politischen Auffassungen haben Doriot und Marcel Déat die linke Herkunft, die Dissidenz von der Mutterpartei sowie einen urspünglich „antifaschistischen“ Impuls gemeinsam. Gleichfalls konnten beide bis Kriegsbeginn keinen anhaltenden Erfolg verbuchen, erst unter deutscher Besatzung spielten sie wieder eine politische Rolle. Es ist einleuchtend, daß angesichts der Komplexität solcher Erscheinungen, bei denen sich die Grenzen zwischen rechts- und linksextremen Positionen verwischen, die Etikettierung mit einem wie auch immer gearteten Faschismus-Begriff unangemessen bleiben muß112.

Für die weitere Entwicklung in den dreißiger Jahren wurden indessen nicht diese linken Dissidenz-Gruppierungen wichtig, sondern die "Croix de Feu“"113. Bei ihr handelte es sich noch mehr als bei den extremistischen Gruppen der zwan-

110 Vgl. die umfassende Biographie von Jean-Paul Cointet, Marcel Déat. Du socialisme au nationalsocialisme, Paris 1998; sowie die einschlägigen Partien in den Arbeiten von Brender, Kollaboration; und Burrin, Dérive fasciste. Für eine vorsichtig differenzierende Interpretation siehe Wirsching, Weltkrieg, S. 492 ff., der an den „Wurzeln des Neosozialisten und späteren Kollaborateurs Marcel Déat [...] die Revision des Sozialismus" liegen sieht.

i11 Vgl. Handourtzel/Buffet, Collaboration.

112 In Deutschland gibt es kein bedeutendes Beispiel linker Dissidenz, die eine rechtsextreme Wendung vollzogen hat.

113 Hierzu Philippe Machefer, Le Parti Social Français, in: Edouard Daladier, Chef du Gouvernement. Sous la direction de René Rémond et Janine Bourdin, Paris 1977; sowie ders., Le Parti Social Français en 1936-1937, in: L'Information Historique 34, Nr. 1 (1972) S. 74-80 und seine mir freundlichst zur Verfügung gestellte, wegen seines Ablebens unvollendet gebliebene Habilitationsschrift über den „Croix de Feu“/PSF stimmen damit ungefähr überein. Vgl. auch Philippe Rudaux, Les Croix de Feu et le P.S.F., Paris 1967; und Else Bierendempfel, Die Bewegung der Feuerkreuzler (Croix de Feu) in Frankreich, Diss. phil. Jena 1938. Die folgenden Ausführungen beruhen auf meiner Auswertung der Polizeiakten in: AN F7-13.042, 13.326, 13.327, 12.950, 13.241, und der Polizei-Präfektur Ba 1901, 1902. 
ziger Jahre um eine militante Protestbewegung. Unter dem steigenden Krisendruck protestierten ihre Anhänger gegen die unzureichende Berücksichtigung ihrer Interessen. Sie sahen darin ein Versagen der republikanischen Institutionen. Die „Croix de Feu“, die sich unter ihrem Anführer Colonel de La Rocque durchaus der Protektion prominenter Politiker der gemäßigten Rechten erfreuten, formten sich 1936 im Moment des Verbotes der Ligen durch die Volksfront-Regierung zu einer politischen Partei um, dem Parti Social Français (PSF). Das versuchten auch etliche andere vom Verbot bedrohte ligistische Gruppierungen, aber nur die „Croix de Feu“ hatte dabei mit dem PSF Erfolg. Das verdankte sie nicht zuletzt auch ihren modernen Methoden der politischen Mobilisierung: einer zentral gelenkten Propaganda, Massenaufmärschen, Automobil-Einsatz. Sie zogen auf diese Weise erhebliche Teile des wachsenden Protestpotentials an sich ${ }^{114}$. Die "Croix de Feu“/PSF vertraten politisch breite Teile des bäuerlichen und gewerblichen Mittelstandes. Insofern integrierten sie erhebliche Teile der traditionellen Anhänger der klein- und mittelständischen Radicaux-Klientel, aber auch jener Landwirte, die sich offenkundig nicht mehr effektiv genug von den spezifischen bäuerlichen Protestgruppen - wie der von Dorgerès -repräsentiert sahen. Die "Croix de Feu“ vertraten aber auch jene "neue Klasse" der modernen Dienstleistungs- und Industriegesellschaft, die aufsteigenden Berufs- und Sozialgruppen, deren aktivistischste Elemente sich zuvor im "Faisceau" engagiert hatten ${ }^{115}$. Sie fanden nun angesichts der Linksöffnung des Regimes und unter dem Eindruck der mangelnden sozio-ökonomischen Krisenbewältigungskapazität des Parlamentes in den „Croix de Feu“/PSF ein Instrument zur Artikulation ihres Protests und eine Hoffnung zur Wahrung ihrer spezifischen Interessen ${ }^{116}$. Die Anhängerschaft dieser Gruppierung stieg zwischen 1933 und 1937 explosionsartig von 30000 auf etwa 700000 an ${ }^{117}$. Sie könnte wohl als eine Art protestlerische „Volkspartei mit Mittelstandsbauch" 118 angesehen werden, aber sie war ganz gewiß keine

114 Nach Soucy, Second Wave, S. 107, hatte sie im Jahr 1932 etwa 25000 Anhänger, für Anfang 1936 geben die Polizeiakten die Zahl von 500000 Anhängern an; vgl. im Archiv der Polizei-Präfektur Ba 1901.

115 Vgl. die Angaben zur Sozialstatistik des PSF in Le Flambeau vom 5. 6. 1937 (zit. nach Bierendempfel, Die Bewegung der Feuerkreuzler, S. 27): 23 Prozent Bauern, 18 Prozent Arbeiter und Handwerker, 34 Prozent Angestellte und kaufmännische Gewerbetreibende, 25 Prozent freie Berufe, Rentiers, Pensionäre. Die aus den Akten erarbeiteten Angaben bei Machefer, Le Parti Social Français, in: Rémond/Bourdin (Hrsg.), Daladier; sowie ders., Le Parti Social Français en 1936-1937, in: L'Information Historique 34, Nr. 1 (1972,) S. 74-80; und in seiner unvollendeten Habilitationsschrift über den „Croix de Feu“/PSF stimmen damit ungefähr überein.

116 Vgl. auch die Angaben bei Wirsching, Weltkrieg, S. 481 ff., der allerdings zu einem verzerrten Ergebnis kommt, da er in seiner Interpretation "alten" und "neuen“ Mittelstand nicht trennt. Tut man dies jedoch, kommt man auf 40,9 Prozent Angestellte von Banken, Versicherungen, Handel, öffentl. Dienst, Transport u. Verkehr, dazu müßte man auch noch 5,1 Prozent Presse, Journalisten etc. rechnen, dagegen machten kleine Gewerbetreibende nur 8,1 Prozent aus. Immerhin waren Arbeiter mit 15,3 Prozent vertreten. Die Statistiken zeigen auch eine erhebliche Anzahl jugendlicher Anhänger.

117 PP-Ba 1901, Februar 1936. Zum Vergleich: im selben Zeitraum steigerte sich die Mitgliederzahl der SFIO von 135000 auf rund 220000 und der PCF von 35000 auf etwa 300000 . Doriots PPF hatte 1936/37 etwa 100000 Anhänger; vgl. Brunet, Doriot, S. $229 \mathrm{f}$.

118 Vgl. die Kennzeichnung als „Volkspartei des Protestes“ bei Thomas Childers, The Social Basis of the National Socialist Vote, in: Journal of Contemporary History 11 (1976), S. 17-42; und ders., The Nazi Voters. The Social Foundations of Fascism in Germany, 1919-1933, Chapel Hill, London 1983; Jürgen W. Falter, Hitlers Wähler, München 1991; und Jürgen W. Falter/Michael H. Ka- 
„negative Volkspartei“ (H. Mommsen) wie die NSDAP, die das bestehende politische System grundsätzlich ablehnte und zerstören wollte. Denn daß die „Croix de Feu“/PSF nicht auf Umsturz der republikanischen Ordnung abzielten, geht sowohl aus ihrem Verhalten am 6. Februar 1934 hervor, an dem gerade durch ihr diszipliniertes Auftreten ein Sturm auf das Palais Bourbon verhindert wurde119, als auch aus ihrer konkreten Politik, vor allem aus ihrem wahl- und parlamentspolitischen Verhalten in der Folgezeit.

Ihre ideologischen und programmatischen Aussagen reflektieren außerdem alles andere als eine der nationalsozialistischen Doktrin analoge Weltsicht. Massive Kritik am Parlamentarismus der damaligen Zeit verband sich mit militantem Antikommunismus. Das eine darf nicht mit grundsätzlichem Antiparlamentarismus verwechselt werden; das andere nicht mit der rassistisch aufgeladenen Ideologie der Hitler-Bewegung. Formeln wie jene, man sei nicht rechts noch links, sondern französisch, oder der Slogan: „Solange ein Parlament wie das gegenwärtige bestehe, gebe es keine Hoffnung“, ebenso wie die Kritik an der „Demagogie“ und der „Korruption“ der Abgeordneten, verweisen auf eine Auffassung, die am Parlament die mangelnde Problemlösungskapazität und die unzulängliche Berücksichtigung der eigenen Interessen kritisiert, nicht aber auf die Absicht, das parlamentarische System der Republik abzuschaffen. Außerdem kommt darin die Ablehnung der Volksfront-Mehrheit der 1936 gewählten Abgeordneten-Kammer zum Ausdruck. Es ist gewiß fehlleitend, in der polarisierend zugespitzten Agitation während der Volksfront-Phase eine Ideologie der bipolaren Weltsicht zu sehen oder die Betonung des Gemeininteresses vor den Individualinteressen als ein "normatives Konzept einer organisch gegliederten Gesellschaft" aufzufassen, mit der sich die "Croix de Feu“/PSF "von der etablierten republikanischen Kultur" entferne. Eine solche Interpretation nimmt Propaganda und polarisierende Agitation für die Substanz. Man könnte einwenden, die Versicherungen der republikanischen Loyalität und des Respektes vor den republikanischen Institutionen und der „légalité républicaine“, die in den Quellen ${ }^{120}$ in reichem Maße zu finden sind, seien nur Ausdruck einer raffinierten, letztlich destruktiven Legalitätstaktik ${ }^{121}$. Das Problem solcher konkurrierender Interpretationen läßt sich nur lösen, indem man die konkrete, tatsächlich durchgeführte Politik der „Croix de Feu“/PSF betrachtet und sich nicht auf die ausufernde politische Rhetorik jener Zeit fixiert, die heute nur zu oft durch die verengte Optik eines nominalistischen „FaschismusBegriffes" analysiert wird ${ }^{122 .}$

ter, Wähler und Mitglieder der NSDAP, in: Geschichte und Gesellschaft 19 (1993), S. 155-177; dazu und zur „Mittelstandsbauch“-These vgl. Jürgen W. Falter, War die NSDAP die erste deutsche Volkspartei? In: Prinz/Zitelmann, Nationalsozialismus und Modernisierung, S. 21-47, hier S. 42.

$119 \mathrm{Zu}$ den Ereignissen um den 6. 2. 1934 vgl. die interessante Interpretation bei Wirsching, Weltkrieg, S. $470 \mathrm{ff}$., dort auch die einschlägige Literatur.

120 Zum Beispiel in François de La Rocque: Service Public, Paris 1934. Vgl. auch die in dieser Hinsicht aufschlußreichen Zitate bei Wirsching, Weltkrieg, S. 489, und vor allem das bei Nobécourt, Le Colonel de La Rocque, ausgebreitete Material.

$121 \mathrm{Vgl}$. Wirsching, Weltkrieg, S. 486. Dagegen Milza, Fascisme Français, S. 135.

122 Das ist gerade hinsichtlich der „Croix de Feu“/PSF m. E. eine Schwäche der ansonsten ausgezeichneten und klugen Arbeit von Wirsching, Weltkrieg. Wirsching muß auch zugeben (S. $489 \mathrm{f}$.), daß die Ideologie der "Croix de Feu“/PSF eine „unoriginelle“ und keine umfassende, sinnstiftende Weltanschauung (S. 488f.) gewesen sei, meint aber dennoch auf Grund von Äußerlichkeiten „ein- 
Der Befund ist eindeutig: im Verlauf der letzten drei Jahre vor Kriegsbeginn hat sich der PSF zunehmend als stabilisierendes Element des republikanischen Regimes bewährt. Eindeutig hat er sich in dieses Herrschaftssystem integriert. Eindeutig ist auch, daß im Gegensatz zur NSDAP (und zur KPD) mit ihren paramilitärischen Verbänden die entsprechenden Gruppen der „Croix de Feu“/PSF nicht einmal tendenziell die Vernichtung des politischen Gegners zum Ziel hatten. Sie waren eher vorbeugende Abwehrmaßnahmen gegen einen als möglich erachteten kommunistischen Umsturzversuch, soweit sie nicht bloß pseudo-militärische Mobilisierungsaktionen und propagandistisches Instrument waren. Der massiv vorgetragene Antikommunismus enthüllt sich bei genauer Betrachtung zudem als kämpferisch-diffamierende Chiffre für die gesamte Linke: bei ihrer diesbezüglichen Agitation machte der „Croix de Feu“/PSF nämlich keinen Unterschied zwischen Radicaux, SFIO und PCF123. Das zeigt, daß hier alles andere als ideologischer „Vernichtungs-Antikommunismus“ im Sinne Hitlers am Werk war. Es ging um Machterlangung durch eine breite Anti-Volksfront-Gruppierung - ein Ziel, das man in gewisser Weise dann 1938 unter Daladier erreichte.

Die Unterschiede zu Deutschland sind offenkundig: dort wurde die parlamentarische Republik erdrückt, weil die „republikanische Mitte“ - Zentrum, Demokraten und Sozialdemokraten - unter dem Druck der system-feindlichen linken (KPD) und rechten (von der DNVP bis zur NSDAP reichenden) Extreme zusammenschmolz ${ }^{124}$. In Frankreich dagegen reagierte das politische System flexibel: Die bislang außerhalb der republikanischen Synthese stehende SFIO wurde durch die Volksfront-Regierung voll in das bestehende System integriert; der kommunistische PCF fügte sich aus strategischen Erwägungen und mit grundsätzlichen, aber taktisch zurückgenommenen Vorbehalten in die Spielregeln des Systems. So wurde eine für die Durchführung von sozio-ökonomischen Reformen ${ }^{125}$ notwendige politisch-parlamentarische Basis wiedergewonnen. Die Volksfront-Taktik des PCF führte faktisch zu einer „Stützung auf Widerruf“ der bürgerlichen Republik ${ }^{126}$. Diese strategische Wendung Moskaus, die der Taktik des PCF zugrundelag, wurde jedoch erst auf Grund der Machterlangung Hitlers in Deutschland vollzogen ${ }^{127}$. Der 30. Januar 1933 war somit Voraussetzung für die system-stabilisierende Haltung des PCF. Allerdings besaß der PCF bis 1934 keineswegs das po-

deutig totalitäre Tendenzen“ feststellen zu können (S. 490). Der ebd., S. 491, zitierte Vorwurf Doriots gegen de La Rocque, er wolle eine "totalitäre Partei" aufbauen, ist gewiß kein wissenschaftlich tragfähiger Beweis; handelte es sich doch schlicht um eine Argumentation im Machtkampf zwischen den beiden um die Führung einer großen Anti-Volksfront-Bewegung.

${ }^{123}$ Das sieht Wirsching, Weltkrieg, S. 487 ff., durchaus, da er aber nicht nur die Radicaux (zu Recht), sondern auch die SFIO (zu Unrecht) als „politische Mitte“ (ebd., S. 488) ansieht, kann er dem PSF republikfeindlichen "rechten" Extremismus unterstellen.

124 Was nicht vergessen lassen soll, daß es schließlich die konservativ-nationalistischen Kräfte waren, die Hitler 1933 an die Macht brachten.

125 Etwa die Accords Matignon, mit denen Frankreich den drängendsten Nachholbedarf in der Entwicklung zum modernen Sozialstaat aufholte, u.a. die Kooperation von Arbeitgebern und Gewerkschaften - eine Art ZAG à la Française.

126 Doriot hatte als Mitglied des Politbüros des PCF eine solche Politik bereits nachdrücklich gefordert, wurde aber marginalisiert und aus der Partei herausgedrängt. Dann erst erfolgte die strategische Wende Moskaus, die Thorez mit dem PCF in Frankreich nachvollzog.

127 Darauf hat Wirsching, Weltkrieg, S. 605, mit Recht verwiesen. Er schreibt allerdings nur der Volksfront eine das Herrschaftssystem stabilisierende Rolle zu, in "faschismustheoretischer Fixierung“ übersieht er die stabilisierende Politik des PSF völlig. 
litische Gewicht, das die KPD vor 1933 besaß128. Ihre Einbeziehung in die Volksfront-Kombination konnte daher für die anderen Volksfrontpartner weniger bedenklich erscheinen als eine in Deutschland theoretisch denkbare linke „Einheitsfront“. Die Linksöffnung des republikanischen Systems war jedoch nur möglich, weil es seit langem eine solide fundierte republikanische Mitte aus der liberalen Rechten und der jakobinisch-demokratischen Linken gab, die in Deutschland nicht vorhanden war, in Frankreich jedoch eine breite Systembasis bot ${ }^{129}$. Sie hatte zunächst bis zum Ende des Ersten Weltkrieges die Anlagerung von wesentlichen Teilen der konservativen und katholischen Rechten und nun, Mitte der dreißiger Jahre, die Integration der sozialistischen Linken ermöglicht.

Ab 1937/1938 wurden dann in Frankreich auch die in dem PSF sich organisierenden protestlerischen Kräfte schrittweise wieder eingegliedert und die bisher noch nicht integrierten neu aufsteigenden Sozialgruppen weitgehend in das politische System integriert. Das Protestpotential war vor allem als Reaktion auf die Bildung des Volksfront-Bündnisses zahlenmäßig ,in einem gewaltigen antikommunistischen Schub" 130 enorm angewachsen. Ihre Integration in das Herrschaftssystem läßt sich an der Politik der PSF-Führung und insbesondere am Abstimmungsverhalten der dem PSF zuzurechnenden Abgeordneten in der Regierungszeit Daladiers erkennen ${ }^{131}$. Bei den verschiedenen Nachwahlen stellte der PSF entweder eigene Kandidaten auf oder unterstützte die Anti-Volksfront-Kandidaten der gemäßigten Rechten ${ }^{132}$. Die Gruppe der PSF-Abgeordneten im Parlament ${ }^{133}$ ebenso wie der Parteiapparat des PSF außerhalb der Kammer trugen jene pragmatischen Modifikationen des politischen Systems mit, die Daladier ein effektives Krisenmanagement erlaubten, also etwa das Regieren durch „décrets-

1281933 hatte der PCF 35000 Mitglieder im Gegensatz zur SFIO mit damals 135000 Mitgliedern, 1935 schon im Zuge der Volksfront-Mobilisierung waren es 70000 für den PCF gegenüber 130000 der SFIO. Erst Anfang 1936 überrundete der PCF die SFIO mit $280000 \mathrm{zu} 180000$. Zahlenangaben nach Claude Willard, Socialisme et Communisme français, Paris 1967, S. $147 \mathrm{f}$.; vgl. auch die Graphik bei Bernard/Dubief, Decline, S. 318.

129 Wirsching, Weltkrieg, S. 354 ff. und S. 604 ff., verweist in überzeugender, subtiler Analyse auf die in den französischen nationalen Mythen vorhandenen Symbole, die der PCF in dieser Situation taktisch geschickt aufnehmen konnte, wie die Marseillaise, die Tricolore, ja sogar den St. Jeanne d'Arc-Mythos. Eine Analogie dazu wäre in Deutschland die symbolisch-taktische Usurpation des "Preußentums" ("Tag von Potsdam") durch Hitler.

130 Wirsching, Weltkrieg, S. 609.

131 Dazu die eingehenden Untersuchungen von Philippe Machefer, François Goguel und Gilles LeBéguec, in: Rémond/Bourdin (Hrsg.), Daladier; vgl. auch Nobécourt, Le colonel de La Rocque, speziell Kap. 46 und 47. Nobécourt spricht auf S. 647 von einem „processus d'admission complète du PSF dans le système“. Vgl. auch Élisabeth du Réau, Edouard Daladier 1885-1946, Paris 1996, S. 216-233, S. $264 \mathrm{ff}$.

132 Vgl. Nobécourt, Le colonel de La Rocque, S. 643-647. Der PSF nahm an den 34 Nachwahlen zwischen 1936 und 1939 teil, ebenso an den Kantonalwahlen vom 10. Oktober 1937 mit Listenverbindungen in 80 Departements. Es gibt noch keine genauen Untersuchungen über die parteipolitische Herkunft der PSF-Wähler, es kann aber davon ausgegangen werden, daß - ähnlich wie bei der NSDAP (Vgl. Falter,Volkspartei, S. 32) - ein erheblicher Teil zuvor für die Parteien der Mitte, vor allem die Radicaux, gestimmt haben. Auch ist von einem beachtlichen Anteil von Jungwählern auszugehen. Vgl. die aufschlußreichen Angaben bei Rudaux, Les Croix de Feu, S. 244-253: „L'activité électorale“. Nach PSF-Angaben kamen aus ihren Reihen 11 Abgeordnete, 198 conseillers généraux, 344 conseillers d'arrondissement, 2692 Bürgermeister und 10257 Stadträte.

133 Dort hatte sich eine PSF-Gruppe von zunächst sechs Angeordneten etabliert, die dann auf elf anwuchs. Dazu gab es noch ein „Comité de sympathie PSF“ und einen „intergroupe parlementaire PSF“ unter den Abgeordneten; vgl. Nobécourt, Le colonel de la Rocque, S. 644. 
lois" und durch (verfassungsmäßig durchaus legitime) plebiszitäre Prozeduren ${ }^{134}$. Es kann kein Zweifel bestehen - so resumiert Machefer die Lage ${ }^{135}$ - daß der PSF allmählich „un parti comme les autres" geworden ist. Dafür spricht auch, daß die gegen ein solches "ralliement républicain" eingestellten Falken inzwischen die Partei verlassen hatten und den Kurs des Colonel de La Rocque dann von außerhalb auf das heftigste kritisierten. Alles in allem war das Verhalten des PSF genau das Gegenteil dessen, worauf die Nationalsozialisten in Deutschland mit ihrem „Elektoralismus" abzielten: innerhalb des Reichstages die Funktionsunfähigkeit des Parlamentes herbeizuführen! Kann man also eine Partei wie den PSF, der sich in das parlamentarische System der Republik integrierte und zu seiner Stabilisierung beitrug, „faschistisch“ oder gar „tendenziell totalitär“ nennen?

Dem Daladierismus mit seiner „majorité de rechange" 136 gelang es, die gröbsten Funktionsstörungen des parlamentarischen System zu beseitigen. Fraglos brachte er eine gewisse Relativierung des „Régime des Assemblées“, sprengte jedoch weder das Verfassungsgefüge der Dritten Republik, noch bewirkte er eine destruktive Umformung des parlamentarischen Systems. Ermöglicht wurde der Daladierismus durch eine Schwerpunkt-Verlagerung innerhalb der Radicaux zur rechten Mitte und durch die Integration der PSF-Kräfte ${ }^{137}$. Diese Mitte-Rechts-Öffnung wurde immerhin von demselben Parlament durchgeführt, das 1936 durch den System-Linksruck die Volksfront-Regierung herbeigeführt hatte - und Daladier war notabene einer der Väter der Volksfront gewesen ${ }^{138}$. Genau dies zeigt schlagend die Flexibilität und Integrationskraft des republikanischen Systems. Im übrigen verstieß der Daladierismus keineswegs gegen die Prinzipien der „republikanischen Moral“ - so wenig wie de Gaulles Fünfte Republik zwanzig Jahre später dies tat, als die neue Verfassung der V. Republik die Allmacht des Parlamentes massiv beschnitt und die präsidiale Exekutive stärkte. Historisch gesehen wies der Daladierismus tendenziell schon auf Elemente der Präsidialverfassung der Fünften Republik voraus. Die zweite Leistung des Daladierismus nach der Integration der Protestbewegungen war die Marginalisierung der nicht integrierbaren systemfeindlichen Kräfte: auf der extremen Linken die Kommunisten; auf der extremen Rechten Doriots PPF sowie die aus den verschiedenen Ligen und extremen Bewegungen hervorgegangenen Splitterparteien. 1939 waren diese Gruppierungen nicht mehr von politischer Bedeutung. Es war nicht allein die relative „Pazifizie-

$134 \mathrm{Zu}$ Daladier und zum „Daladierismus“ vgl. außer dem genannten Sammelband von Rémond/ Bourdin (Hrsg.), Daladier; und dies., La France et les Français en 1938-1939, Paris 1978; und vor allem die große Biographie von du Réau, Daladier, speziell auch S. 215-233, S. 288-299 und S. 311328.

135 Machefer, unveröff. Manuskript seiner Habilitationsschrift, vol. I, Kap. XXI „Face à Daladier“, S. 483-485.

136 Daladier bildete ein radikalsozialistisches Kabinett ohne die Sozialisten, aber mit Vertretern der gemäßigten Rechten; vgl. du Réau, Daladier, S. 215-233.

137 Vgl. Nobécourt, Le colonel de La Rocque, S. 647: "La convergence avec les radicaux“.

138 Bedeutsam ist in diesem Zusammenhang, daß schon 1936 etwa ein Drittel der radikal-sozialistischen Abgeordneten der Volksfront distanziert gegenüberstanden. Viele von diesen waren in der Stichwahl mit den Stimmen der Rechtswähler gewählt worden, was ihnen die spätere Umorientierung erleichterte. Vgl. Georges Dupeux, Le Front Populaire et les Élections de 1936, Paris 1959; Paul Warwick, The Popular Front: A Legislative Analysis, London 1977; sowie Maurice Larkin, France since the Popular Front. Government and People 1936-1986, Oxford 1988. 
rung" des PCF, welche den rechtsextremen Gruppierungen ihre Virulenz nahm ${ }^{139}$, sondern auch die Integration des großen Protestpotentials. Als hilfreich erwies sich dabei natürlich der wirtschaftliche Aufschwung, der ab 1938 spürbar wurde. Wichtig war aber auch eine langfristig eingewurzelte republikanische Tradition, die selbst modernistische Systemveränderer wie den „Faisceau“ und die S.F. veranlaßte, aufrichtig oder taktisch-propagandistisch, sich stets auf die „republikanische Moral" und die Ideen der französischen Revolution zu berufen ${ }^{140}$.

Das politisch-gesellschaftliche System der vielgescholtenen, oft verachteten Dritten Republik erwies sich demnach trotz all ihrer Defizite als durchaus flexibel und integrativ. Trotz aller Belastungen und trotz aller aggressiven Polarisierung hielt der republikanische Herrschaftskonsens. Die Republik bedurfte keiner links- oder rechtsextremistischen Systemveränderer. Die republikanische Synthese war flexibel genug und vermochte - wenngleich nicht ohne Schwierigkeiten, am Ende jedoch relativ effektiv - die Krisenlagen der Zwischenkriegszeit zu bewältigen.

Im Gegensatz zum parlamentarischen System der Republik von Weimar konnte das französische "Régime des Assemblées“ auch deswegen so flexibel reagieren, weil erstens der Integrationsprozeß der konservativen Rechten in die parlamentarische Republik entscheidend fortgeschritten war - während diese in Deutschland die Republik grundsätzlich ablehnte und sich am „starken“ Obrigkeitsstaat von vor 1914 orientierte -, weil zweitens die kommunistische Partei, der Weisung der Komintern folgend, sich einer Zusammenarbeit mit den die Republik tragenden Kräften in der Volksfront öffnete - wohingegen in Deutschland der Kampf der KPD und der konservativen Rechten gegen die tragenden Kräfte der Weimarer Republik zu deren Zerstörung beitrug -, schließlich drittens, weil die jakobinisch-liberale Mitte - die in Deutschland praktisch nicht existierte - breit gelagert und seit langem gewohnt war, sich für Kombinationen nach der einen wie der anderen Seite offen zu zeigen. So gelang der Republik die Krisenbewältigung. Schließlich war das republikanisch-parlamentarische System in Frankreich spätestens seit 1878 fest verankert. Es hatte eine lange „Eingewöhnungsperiode“ hinter sich, welche die Entwicklung eines „esprit républicaine“ ermöglichte; wohingegen in Deutschland der noch jungen parlamentarischen Republik Zeit und Möglichkeit zur historischen Einwurzelung fehlte. Daher erwartete man, orientiert an preußisch-deutscher Obrigkeitsstaats-Tradition, in Krisensituationen nicht das Heil von Parlament und Parteien, sondern vom Reichspräsidenten. Anders als die Republik von Weimar ging Frankreichs Dritte Republik nicht an sich selbst zugrunde, sondern erst unter dem Ansturm deutscher Panzer ${ }^{141}$.

${ }^{139}$ Das betont Wirsching, Weltkrieg, nachdrücklich. Er hebt die pazifizierende Wirkung der Volksfront und der politischen Kultur Frankreichs hervor, welche den politischen Extremismus beider Seiten domestiziert habe; vgl. u.a. S. 610. Das ist gewiß richtig gesehen, verkennt aber doch die zentrale Bedeutung des anderen entscheidenden Faktors: die Mitte-Rechts-Öffnung durch den Daladierismus, der zur Stärkung der Exekutive, zur Integration der einen großen extremistischen Protestpartei (PSF) und zur Marginalisierung der anderen (PPF) führte.

140 Vgl. Michel Winock, Histoire de l'extrême droite en France, Paris 1993, S. 302: „[...] l'esprit républicaine [...] le réflexe de ,défense républicaine‘ est devenu familier aux Français".

141 Die während des Drôle de Guerre aufbrechenden Desintegrationsmomente analysierte in seiner Freiburger Dissertation (1987) eingehend Hans-Jürgen Heimsoeth, Der Zusammenbruch der Dritten Französischen Republik. Frankreich während der „Drôle de Guerre“ 1939/40, Bonn 1990. 